\title{
Fisetin Confers Cardioprotection against Myocardial Ischemia Reperfusion Injury by Suppressing Mitochondrial Oxidative Stress and Mitochondrial Dysfunction and Inhibiting Glycogen Synthase Kinase $3 \beta$ Activity
}

\author{
Karthi Shanmugam, ${ }^{1}$ Sriram Ravindran, ${ }^{1}$ Gino A. Kurian $\mathbb{D}^{1},{ }^{1}$ and Mohanraj Rajesh ${ }^{2}{ }^{2}$ \\ ${ }^{1}$ SASTRA Deemed University, Vascular Biology Laboratory, School of Chemical and Biotechnology, Thanjavur, \\ Tamil Nadu 613401, India \\ ${ }^{2}$ Department of Pharmacology and Therapeutics, College of Medicine and Health Sciences, UAE University, Al Ain 17666, UAE \\ Correspondence should be addressed to Gino A. Kurian; kurian@scbt.sastra.edu and Mohanraj Rajesh; rajm@uaeu.ac.ae
}

Received 15 November 2017; Accepted 1 January 2018; Published 25 February 2018

Academic Editor: Renata Szymanska

Copyright (c) 2018 Karthi Shanmugam et al. This is an open access article distributed under the Creative Commons Attribution License, which permits unrestricted use, distribution, and reproduction in any medium, provided the original work is properly cited.

\begin{abstract}
Acute myocardial infarction (AMI) is the leading cause of morbidity and mortality worldwide. Timely reperfusion is considered an optimal treatment for AMI. Paradoxically, the procedure of reperfusion can itself cause myocardial tissue injury. Therefore, a strategy to minimize the reperfusion-induced myocardial tissue injury is vital for salvaging the healthy myocardium. Herein, we investigated the cardioprotective effects of fisetin, a natural flavonoid, against ischemia/reperfusion (I/R) injury (IRI) using a Langendorff isolated heart perfusion system. I/R produced significant myocardial tissue injury, which was characterized by elevated levels of lactate dehydrogenase and creatine kinase in the perfusate and decreased indices of hemodynamic parameters. Furthermore, I/R resulted in elevated oxidative stress, uncoupling of the mitochondrial electron transport chain, increased mitochondrial swelling, a decrease of the mitochondrial membrane potential, and induction of apoptosis. Moreover, IRI was associated with a loss of the mitochondrial structure and decreased mitochondrial biogenesis. However, when the animals were pretreated with fisetin, it significantly attenuated the I/R-induced myocardial tissue injury, blunted the oxidative stress, and restored the structure and function of mitochondria. Mechanistically, the fisetin effects were found to be mediated via inhibition of glycogen synthase kinase $3 \beta$ (GSK3 $\beta$ ), which was confirmed by a biochemical assay and molecular docking studies.
\end{abstract}

\section{Introduction}

Ischemic heart disease is one of the leading causes of morbidity and mortality worldwide, while effective therapy to limit the spectrum of abnormalities often leads to arrhythmias, myocardial stunning, and necrosis, and these pathological changes are collectively referred to as reperfusion injury (RI) $[1,2]$. Clinically, predicting the onset of RI is challenging, because of the lack of definitive biomarkers. This problem is confounded by the lack of clear understanding of the pathomechanisms involved in RI [3]. Currently, mitochondrial dysfunction, oxidative stress, perturbed cardiomyocyte
$\mathrm{Ca}^{2+}$ homeostasis, inflammation, and apoptosis cascades are recognized as the key drivers for RI-induced myocardial tissue damage $[4,5]$. Therefore, targeting these pathways could be beneficial for preventing RI and could aid in the functional recovery of the myocardium.

Epidemiological studies have indicated that regular consumption of fruits and vegetables containing flavonoids and polyphenols is associated with a reduced risk for the development of cardiovascular diseases, inflammatory diseases, neurodegenerative diseases, and cancer [6]. The underlying mechanisms of several cardioprotective procedures such as ischemic preconditioning for IRI have been linked to the 
inhibition of GSK3 $\beta$, which provides cardioprotection by modulating mitochondrial ATP-sensitive $\mathrm{K}^{+}$channel, the mammalian target of rapamycin (mTOR) signaling pathway, and autophagy [7-9]. Since downstream signaling of GSK3 $\beta$ converges in mitochondria, along with its translocation by ischemic stimuli, studying the action of natural compounds on reversing mitochondrial dysfunction, the key player in the pathology of I/R, by modulating GSK $3 \beta$ will provide the impetus for the development of small molecules as selective GSK3 $\beta$ inhibitor $[8,10]$. Fisetin is a natural flavonoid found in several fruits and vegetables [11]. The compound has been reported to elicit antioxidant and anti-inflammatory effects, retard the development of atherosclerosis, and exhibit neuroprotective properties in several preclinical studies [11]. In this study, we investigated the cardioprotective effects of fisetin against IRI using a Langendorff isolated heart perfusion system. In addition, in in silico and molecular docking studies, using the crystal structure of GSK3 $\beta$, a library of polyphenolic compounds was screened by energy-optimized pharmacophore-based virtual screening to identify a molecule with the best-suited structural orientation for GSK3 $\beta$ inhibition. Since fisetin emerged as the prime candidate for a GSK3 $\beta$ inhibitor, its cardioprotective activity was validated using an isolated rat heart model of IRI.

\section{Materials and Methods}

2.1. Animals and Chemicals. All animal experimental procedures were conducted according to the guidelines of the Committee for the Purpose of Control and Supervision of Experiments on Animals (CPCSEA), Government of India. A prior approval for the conduct of experiments was obtained from the Institutional Animal Ethical Committee (IAEC) at SASTRA Deemed University, Thanjavur, India. Male Wistar rats (250-300 g) used in the study were inbred at the central animal facility, SASTRA University. All the animals were housed in ventilated polycarbonate cages and provided access to food and water ad libitum. Unless specified, all fine chemicals were procured from Sigma-Aldrich (St. Louis, MO, USA).

2.2. Isolated Rat Heart Model of Ischemia Reperfusion Injury. Isolated mammalian heart model according to Langendorff was used for establishment of myocardial IRI [12]. The ex vivo method involved anesthetization of a rat (ketamine $80 \mathrm{mg} / \mathrm{kg}$ + xylazine $20 \mathrm{mg} / \mathrm{kg}$ ) followed by the excision of heart and perfusion with Krebs-Henseleit buffer $(118.0 \mathrm{mM}$ $\mathrm{NaCl}, 4.7 \mathrm{mM} \mathrm{KCl}, 1.9 \mathrm{mM} \mathrm{CaCl} 2,1.2 \mathrm{mM} \mathrm{MgSO}_{4}$, $25.0 \mathrm{mM} \mathrm{NaHCO}_{3}, 1.2 \mathrm{mM} \mathrm{KH}_{2} \mathrm{PO}_{4}$, and $10.1 \mathrm{mM}$ glucose, $\mathrm{pH}$ 7.4), maintained at $37^{\circ} \mathrm{C}$ with continuous oxygenation $\left(95 \% \mathrm{O}_{2}+5 \% \mathrm{CO}_{2}\right)$. The heart was stabilized for $20 \mathrm{~min}$ on the perfusion system (ADInstruments, Bella Vista, New South Wales, Australia) by maintaining a constant perfusate pressure of $70 \mathrm{mmHg}$. Hemodynamic changes were monitored using a pressure transducer connected to a latex balloon placed in the left ventricle. Electrical recordings were continuously made using a PowerLab data acquisition system (ADInstruments) and analyzed using the LabChart Pro 8 software (ADInstruments) [12].
The experimental groups included sham, fisetin + sham, $\mathrm{I} / \mathrm{R}$ alone, and fisetin pretreatment, followed by I/R (fisetin $+\mathrm{I} / \mathrm{R})$. Fisetin $(20 \mathrm{mg} / \mathrm{kg}$; TOCRIS Bioscience, Bristol, UK) was injected intraperitoneally $1 \mathrm{~h}$ before the induction of ischemia. We performed pilot experiments to ascertain a suitable dosage regimen of fisetin, and our observations revealed that administration of fisetin at $(20 \mathrm{mg} / \mathrm{kg})$ consistently provided the optimal cardioprotection. Therefore, we adopted this dose for further experiments.

A typical $\mathrm{I} / \mathrm{R}$ protocol consisted of $30 \mathrm{~min}$ of ischemia induced by stopping the buffer flow, followed by $60 \mathrm{~min}$ of reperfusion induced by resuming the flow. Throughout the duration of the experiment, hemodynamic parameters were continuously monitored and the perfusate was collected at the end of reperfusion for biochemical analysis. At the end of the experiment, the hearts were immediately frozen in liquid nitrogen and stored at $-80^{\circ} \mathrm{C}$ until further analysis.

\subsection{Functional and Morphological Assessment of Cardiac} Injury. Cardiac injury was assessed by measuring the levels of lactate dehydrogenase (LDH) and creatine kinase (CK) released into the perfusate after ischemic injury. LDH was estimated spectrophotometrically at a wavelength of $340 \mathrm{~nm}$ based on the conversion of lactate to pyruvate and expressed as $\mathrm{NADH}$ oxidized/min/mg protein [13]. CK was estimated based on the amount of inorganic phosphate formed from ATP, with 1-amino-2-naphthol-4-sulphonic acid (ANSA) reagent and measured at $640 \mathrm{~nm}$ [13]. Heart sections were stained using triphenyl tetrazolium chloride (TTC) to calculate the percentage of the infarcted area. Measurement of the infarct size was performed as described previously [14]. Briefly, heart sections were incubated in 1.5\% TTC prepared in $\mathrm{PBS}$ for $10 \mathrm{~min}$ at $37^{\circ} \mathrm{C}$. Images were acquired using a zoom stereomicroscope (NIKON-SMZ1270) equipped with a high-definition CCD camera (NIKON-DS-Fi2), and the NIS Elements documentation software. The ImageJ software (NIH-USA) was used for the measurement of the infarcted area [14].

2.4. Isolation of Subcellular Organelles (Mitochondria, Lysosomes, and Microsomes). Cardiac mitochondria were isolated by differential centrifugation as described previously [15], and microsomes and lysosomes were isolated using sucrose density gradients as described by Graham [16]. Briefly, a $10 \%$ heart homogenate was prepared in isolation buffer (220 mM mannitol, $70 \mathrm{mM}$ sucrose, $5 \mathrm{mM}$ MOPS, $2 \mathrm{mM}$ EDTA, and $0.2 \% \mathrm{BSA}, \mathrm{pH} 7.4$ ) and centrifuged at $500 \times \mathrm{g}$ for $10 \mathrm{~min}$ at $4^{\circ} \mathrm{C}$, to pellet the nuclear fraction. The resulting supernatant was centrifuged at $12,000 \times \mathrm{g}$ for $10 \mathrm{~min}$ at $4^{\circ} \mathrm{C}$ to obtain a crude mitochondrial fraction consisting of light and heavy mitochondria as well as lysosomes. In the subsequent step, the supernatant, consisting of microsomes, was ultracentrifuged (Beckman Coulter, Indianapolis, IN, USA) at $100,000 \times \mathrm{g}$ for $40 \mathrm{~min}$ at $4^{\circ} \mathrm{C}$ to collect microsomes, and the supernatant was used as the cytosolic fraction for further analysis. The microsomes were resuspended in storage buffer $(0.25 \mathrm{M}$ sucrose, $1 \mathrm{mM}$ EDTA, and $10 \mathrm{mM}$ HEPES adjusted to $\mathrm{pH}$ 7.4). 
The crude mitochondrial pellet was subjected to sucrose density gradient separation as reported earlier [17]. Briefly, a sucrose density gradient $(1.25,1.22,1.19,1.15,1.11$, and $1.09 \mathrm{~g} / \mathrm{cm}^{3}$ ) was prepared in PBS ( $\left.\mathrm{pH} 7.4\right)$ and layered in a $5 \mathrm{~mL}$ centrifuge tube. The crude mitochondrial pellet was resuspended in PBS, then layered on top of the density gradient, and centrifuged in a swingout bucket rotor at 100,000 $\times \mathrm{g}$ for $3 \mathrm{~h}$ at $4^{\circ} \mathrm{C}$ using the lowest acceleration and deceleration speeds. Based on their densities, lysosomes $\left(1.12 \mathrm{~g} / \mathrm{cm}^{3}\right)$ and mitochondria $\left(1.18 \mathrm{~g} / \mathrm{cm}^{3}\right)$ were separated into two fractions, which were collected and stored in storage buffer $(0.25 \mathrm{M}$ sucrose, $1 \mathrm{mM}$ EDTA, and $10 \mathrm{mM}$ HEPES adjusted to pH 7.4). All the subcellular fractions separated were estimated for their protein content using the Bradford assay reagent (Bio-Rad, Hercules, CA, USA).

2.5. Estimation of Lipid Peroxide, Antioxidant, and Antioxidant Enzyme Activities in Subcellular Compartments. The cytosolic and subcellular fractions isolated as described above were used for the assessment of oxidative stress markers. A thiobarbituric acid reactive species (TBARS) assay based on the formation of malondialdehyde was performed to quantify the amount of lipid peroxidation by using the method of Ohkawa et al. [18]. Briefly, $100 \mu \mathrm{L}$ of a sample was added to the reaction mixture $(0.8 \%$ thiobarbituric acid and $15 \%$ trichloroacetic acid, adjusted to $\mathrm{pH} 3.5$ ), and the mixture was incubated for $1 \mathrm{~h}$ in a water bath maintained at $75^{\circ} \mathrm{C}$. After cooling, a butanol-pyridine mixture $(15: 1)$ was added to extract the pink-colored complex, and the absorbance of the organic layer was read at $532 \mathrm{~nm}$. Malondialdehyde was used as a standard in the assay $[12,13,15]$.

The antioxidant status of the myocardium was evaluated based on the GSH level using Ellman's reagent (5,5' -dithiobis-2-nitro-benzoic acid). GSH concentration was determined according to the method of Sedlak and Lindsay [19]. In brief, phosphate buffer ( $\mathrm{pH} 8), 5 \%$ trichloroacetic acid, and Ellman's reagent were added to a protein sample to observe the color development due to formation of thionitrobenzoate. The absorbance was measured at $412 \mathrm{~nm}$, and the values were expressed as $\mu \mathrm{M} / \mu \mathrm{g}$ of protein using GSH as a standard $[12,13,15]$.

The superoxide dismutase (SOD) activity was determined in cardiac tissues as reported $[12,13,15]$. The assay was based on the ability of SOD, present in the samples, to inhibit the autoxidation of pyrogallol. Briefly, $50 \mu \mathrm{L}$ of a sample was mixed with buffer $(45 \mathrm{mM}$ Tris, $1 \mathrm{mM}$ EDTA adjusted to $\mathrm{pH} 7.4$ ), and $2.5 \mathrm{mM}$ pyrogallol was added to initiate the reaction. The autoxidation of pyrogallol was kinetically monitored at $420 \mathrm{~nm}$ for $5 \mathrm{~min}$, and the SOD activity was calculated based on the ability of 1 unit of SOD to inhibit autoxidation of pyrogallol by $50 \%$.

The catalase activity was determined as reported $[12,13,15]$. Essentially, the reaction buffer $(0.1 \mathrm{M}$ sodium phosphate buffer, pH 7.2, $4 \mathrm{mM} \mathrm{H}_{2} \mathrm{O}_{2}$, and $5 \mathrm{~N} \mathrm{H}_{2} \mathrm{SO}_{4}$ ) was added to $100 \mu \mathrm{L}$ of a sample, and the reaction was initiated by the addition of $0.005 \mathrm{M} \mathrm{KMnO}_{4}$. The rate of the optical density change was kinetically monitored at $515 \mathrm{~nm}$. The enzyme activity was expressed in units/mg protein using the catalase enzyme as the standard.
The glutathione peroxidase (GPx) activity was assayed as reported previously $[12,13,15]$. Briefly, $50 \mu \mathrm{L}$ of a sample was added to the reaction buffer consisting of $10 \mathrm{mM} \mathrm{NaN}_{3}$, $4 \mathrm{mM}$ GSH, and $2.5 \mathrm{mM} \mathrm{H}_{2} \mathrm{O}_{2}$ prepared in phosphate buffer $\mathrm{pH} 7.4$ and incubated for $10 \mathrm{~min}$ at room temperature. The GPx reaction was stopped by adding $10 \%$ trichloroacetic acid, and the unreacted GSH was estimated using $0.04 \%$ Ellman's reagent prepared in 1\% sodium citrate and reading the absorbance at $412 \mathrm{~nm}$ using a spectrophotometer.

The glutathione reductase (GR) activity was assayed as per the method described previously [12, 13, 15]. Briefly, $50 \mu \mathrm{L}$ of a protein sample was added to the reaction mixture $(0.25 \mathrm{M}$ sodium phosphate buffer, $\mathrm{pH} 7.4,0.5 \mathrm{mM}$ EDTA, $4 \mathrm{mM}$ oxidized glutathione, and $0.2 \mathrm{mM} \mathrm{NADPH}$ ) and the oxidation of NADPH was monitored at $340 \mathrm{~nm}$ for $5 \mathrm{~min}$. The values were expressed as units/mg of protein using GR as a standard $[12,13,15]$.

\subsection{Measurement of Energy Metabolism from Electron} Transport Chain Enzyme Activity of Cardiac Mitochondria. The electron transport chain (ETC) enzyme activities were measured in mitochondria based on specific donoracceptor oxidoreductase activities. Complexes I and III were assessed based on the rotenone-sensitive NADHoxidoreductase (NQR) and rotenone-sensitive NADHcytochrome $\mathrm{C}$ reductase (NCCR) activities. The ubiquinol cytochrome $\mathrm{C}$ reductase (QCR) activity was assessed for complex III, while the succinate decylubiquinone 2,6dichlorophenolindophenol (DCPIP) reductase (SQR) and succinate cytochrome $\mathrm{C}$ reductase (SCCR) activities were measured for complexes II and III. The cytochrome $\mathrm{C}$ oxidase (COX) activity was measured as discribed [15]. All kinetic readings were acquired in a high throughput format using a using Synergy $\mathrm{H} 1$ multimode reader (BioTek, USA). The enzyme activities were expressed in $\mu \mathrm{M}$ of $\mathrm{NADH}$ oxidized $/ \mathrm{min} / \mathrm{mg}$ protein (NQR), $\mu \mathrm{M}$ of cytochrome $\mathrm{C}$ reduced $/ \mathrm{min} / \mathrm{mg}$ protein (NCCR, SCCR, and QCR), $\mu \mathrm{M}$ of DCPIP reduced $/ \mathrm{min} / \mathrm{mg}$ protein (SQR), and $\mu \mathrm{M}$ of cytochrome C oxidized/min/mg protein (COX) [15].

2.7. Cardiac Mitochondria Swelling Assay. The mitochondrial swelling assay was performed to assess the functional efficiency of the permeability transition pore in regulation of calcium overload induced by IRI in the myocardium. In brief, the assay was performed by incubating $150 \mu \mathrm{g}$ of mitochondrial protein in swelling buffer $(120 \mathrm{mM} \mathrm{KCl}, 10 \mathrm{mM}$ Tris- $\mathrm{HCl}$, and $5 \mathrm{mM} \mathrm{KH} \mathrm{PO}_{4}, \mathrm{pH}$ 7.4) and monitoring the rate of change in absorbance at $540 \mathrm{~nm}$ after addition of $250 \mu \mathrm{M} \mathrm{CaCl}_{2}$ for $20 \mathrm{~min}$, according to the procedure of Martens et al. [20]. The swelling activity was reported as light scattering/mg protein at $540 \mathrm{~nm}$ [15].

2.8. Determination of Mitochondrial Membrane Potential. The mitochondrial membrane potential, an indicator of the inner and outer membrane integrity, was estimated using the rhodamine 123 (RH123) membrane-sensitive dye and calculated using the Nernst equation according to the method described by Scaduto and Grotyohann [21]. Briefly, $150 \mu \mathrm{g}$ of protein was incubated with $50 \mathrm{~nm} \mathrm{RH123}$ for 
$30 \mathrm{~min}$ at $37^{\circ} \mathrm{C}$. After the incubation, the sample fluorescence outside and inside of the mitochondria was estimated at $\mathrm{ex} / \mathrm{em}=485 / 538 \mathrm{~nm}$, respectively, and the membrane potential $(\Delta \psi)$ was represented in millivolts [15].

2.9. Determination of Mitochondrial Superoxide $\left(\mathrm{O}_{2}{ }^{--}\right)$ Generation. Dihydroethidium [or hydroethidine (DHE)] is an ethidium-based, redox-sensitive fluorescent probe, shown to be oxidized by $\mathrm{O}_{2}{ }^{--}$to form 2-hydroxyethidium (2-OH$\mathrm{E}^{+}$). The assay was performed using the protocol previously adapted from Back et al. [22], and the fluorescence was measured at an excitation wavelength of $500-530 \mathrm{~nm}$ and an emission wavelength of $590-620 \mathrm{~nm}$ using a fluorimeter (Tecan, Switzerland).

2.10. Determination of Apoptosis Markers. Chromatin fragmentation (DNA damage), poly (ADP-ribose) polymerase (PARP) activity, and caspase 3 activity in myocardial tissues were determined as described previously $[23,24]$.

2.11. Examination of Myocardial Ultrastructure. The ventricle section from each tissue was collected after reperfusion for ultrastructural imaging, using a transmission electron microscope (JEM 1400-JEOL, MA, USA). Briefly, tissues were fixed in $4 \%$ glutaraldehyde followed by $0.1 \% \mathrm{OsO}_{4}$ at $8^{\circ} \mathrm{C}$. After dehydration of the sections with graded series of acetone and propylene oxide, the samples were fixed in an epoxy resin to obtain ultrathin sections using an ultra microtome (Ultracut R, Leica GmbH, Wetzlar, Germany). The ultracut sections were stained with uranyl acetate, followed by lead citrate, and imaged on copper grids by applying $80 \mathrm{kV}[13]$.

2.12. Determination of GSK3 $\beta$ Activity. The GSK $3 \beta$ activity in myocardial tissues was determined using an ADP-Glo kinase assay kit (Promega, Madison, WI, USA). In brief, this luminescent kinase assay measures ADP formed in a kinase reaction, which is converted to ATP and then to luminescence with the Ultra-Glo luciferase. Luminescence was measured in a multimode plate reader (Tecan) and was directly proportional to the GSK3 $\beta$ activity present in the samples.

2.13. mRNA Expression of Mitochondrial Biogenesis Markers. Total RNA was extracted using the TRIzol reagent (Thermo Fisher Scientific, MA, USA) according to the manufacturer's protocol. Next, reverse transcription was performed using Verso cDNA synthesis kit (Thermo Fisher Scientific). Realtime PCR reactions were carried out using the DyNAmo Flash SYBR Green qPCR kit (Thermo Fisher Scientific) on a PCR system (ABI 7500, Applied Biosystems, Foster City, CA, USA). The amplification conditions were as follows: initial denaturation at $95^{\circ} \mathrm{C}$ for $2 \mathrm{~min}$, followed by 35 cycles at $95^{\circ} \mathrm{C}$ for $30 \mathrm{sec}$ and $60^{\circ} \mathrm{C}$ for $30 \mathrm{sec}$. The primers used in this study are listed below:

(1) Nuclear respiratory factor 1 (NRF-1)

(a) Sense (5'-GAGTGACCCAAACCGAACA-3')

(b) Antisense (5'-GGAGTTGAGTATGTCCGAGT-3')
(2) Nuclear respiratory factor 1 (NRF-2)

(a) Sense (5'-GCAGGCCAAGATGACGAAGT-3')

(b) Antisense (5'-ACTTACACCGGCTCGGAGAA-3')

(3) Peroxisome proliferator-activated receptor gamma coactivator 1-alpha $(P G C-1 \alpha)$

(a) Sense (5'-GACCACAAACGATGACCCTC-3')

(b) Antisense (5'TGTTGCGACTGCGGTTGT3')

(4) Mitochondrial transcription factor A (TFAM)

(a) Sense (5'-GGTGTATGAAGCGGATTT-3')

(b) Antisense (5'-CTTTCTTCTTTAGGCGTTT-3')

(5) GAPDH

(a) Sense (5'-GGAAGGACTCATGACCACAGT-3')

(b) Antisense (5'-GCCATCACGCCACAGTTTC-3')

\subsection{Molecular Docking Studies for Determining a Potent Inhibitor of GSK3 $\beta$ Activity}

2.14.1. Homology Modelling. Since the experimentally determined structure of GSK $3 \alpha$ was not available, we modeled the protein structure using comparative modeling. The amino acid sequence of GSK $3 \alpha$ with the accession number NP_063937 was downloaded from NCBI protein database. The structure of GSK3 $\alpha$ was modeled using the PRIME module implemented in the Schrodinger Software Suite (Prime, Schrödinger, LLC, New York, NY, 2015). The crystal structure of GSK3 $\beta$ (PDB: 1Q41) with $2.1 \mathrm{~A}^{\circ}$ resolution was downloaded from the RCSB Protein Data Bank (PDB) and used as a template. The quality of the model was evaluated using the discrete optimized protein energy (DOPE) statistical method for assessing homology mapping [25], the Ramachandran plot, Verify3D plot [26], and the ERRAT (program for verifying protein structures determined by crystallography).

2.14.2. Protein Structure Preparation. The atomic coordinates of GSK3 $\beta$ complexed with indirubin- $3^{\prime}$-monoxime (1Q41) were downloaded from the RCSB Protein Data Bank (PDB) [27]. The downloaded structure was prepared using the protein preparation wizard [28], a tool from the Maestro software package (Maestro v9.3, Schrödinger, LLC, New York, NY). Hetero groups were assigned appropriate bond orders. The formal charges were added, and the valences of all atoms in the structure were satisfied with hydrogens. Hydrogen bond network optimization was done by prediction of His tautomers and ionization states, assignment of 1800 rotations of the terminal $\chi$ angle to Asn, Gln, and His residues, and sampling of hydroxyl and thiol hydrogens. The cocrystallized ligand and crystallographic water molecules in the structure were removed. Using the OPLS-2005 force field and restrained minimization protocol, the energy of the protein was minimized with the default constraint of 

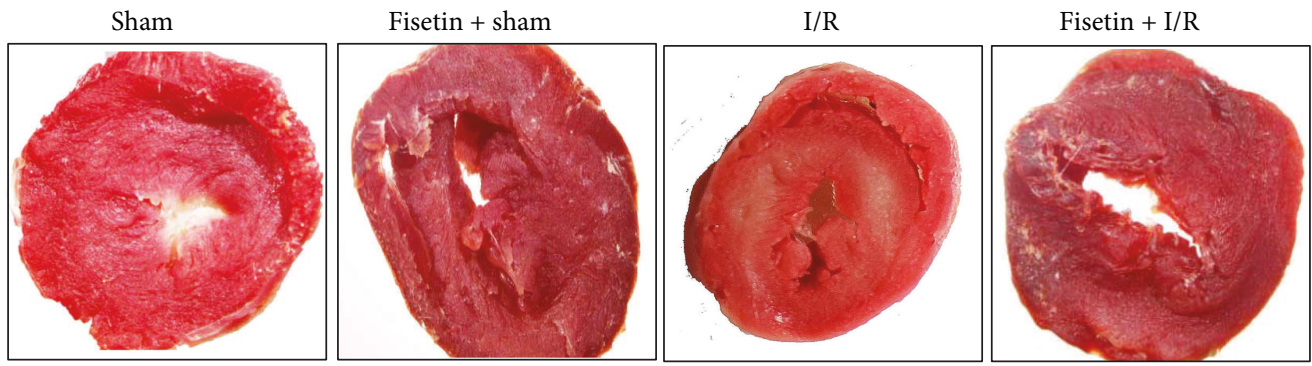

(a)

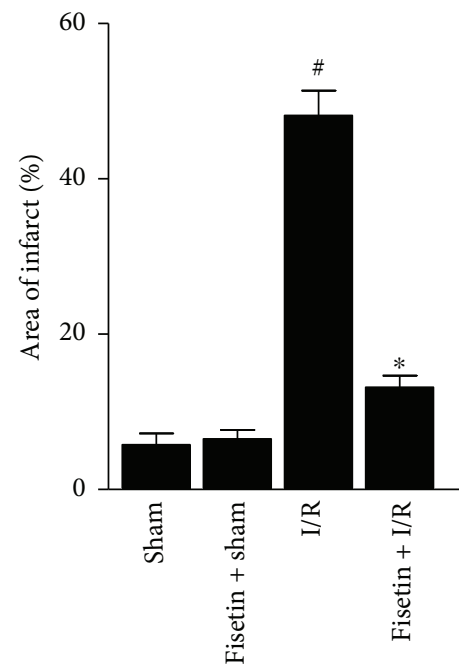

(b)

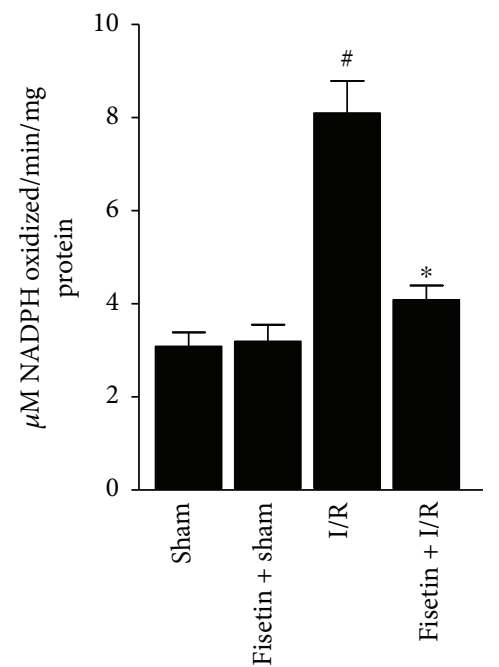

(c)

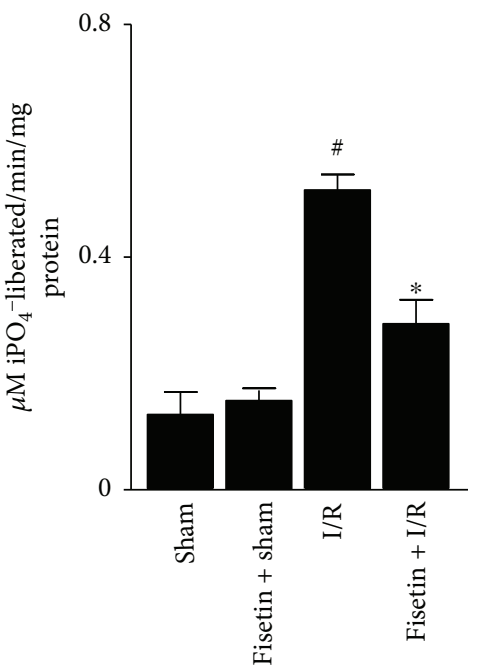

(d)

FIGURE 1: Depicts the effect of fisetin treatment on IRI. (a) Shown are the representative TTC stained sections of heart tissues from the respective groups; (b) the LDH activity in the perfusate and (d) CK activity in the perfusate. $n=6 /$ group; ${ }^{\#} P<0.001$ versus sham/sham \pm fisetin; ${ }^{*} P<0.01$ versus I/R.

$0.30 \mathrm{~A}^{\circ}$ root-mean-square deviation (RMSD). The same protocol was used for preparing the GSK $3 \alpha$ model.

2.14.3. Ligand Docking/Refinement. The structure of fisetin was drawn using MarvinSketch chemical structure drawing software. The energy-minimized 3D structures of fisetin were generated using the LigPrep wizard in the Schrödinger software Suite. All possible ionization states of fisetin were generated in the $\mathrm{pH}$ range of 5-9.

2.14.4. Receptor Grid Generation. The receptor grid was generated using the Schrödinger receptor grid generation wizard. The grid box was kept centered on the cocrystallized ligand, indirubin- $3^{\prime}$-monoxime. The size of the grid box was defined so that it covered the entire ATP-binding site.

2.14.5. Molecular Docking. Molecular docking of fisetin with GSK $3 \alpha$ and GSK3 $\beta$ was performed using the Schrödinger Glide extra precision (XP) algorithm (Schrödinger, LLC) [29]. The default parameters were used, and no constraints were set for the ligand-receptor interactions. The docking results were written as a pose viewer file, and the proteinligand complex interactions were studied using the PyMOL molecular graphics system, version 1.8 (Schrödinger, LLC.).

2.15. Statistical Analysis. Values presented are mean \pm SEM. Statistical fitness of the data was analyzed using the
GraphPad Prism 7.0 program (GraphPad Software, La Jolla, CA, USA). One-way analysis of variance (ANOVA) was used to determine significant differences between the groups, and post hoc Dunnet's test was employed to determine the difference among the groups, $P<0.05$ was considered statistically significant.

\section{Results}

3.1. Fisetin Attenuates I/R-Induced Myocardial Tissue Injury. As shown in (Figures 1(a) and 1(b)), TTC staining revealed a marked increase in the infarct size in the animals subjected to I/R. However, this effect was attenuated when animals were pretreated with fisetin. Further, analysis of LDH (Figure 1(c)) and CK (Figure 1(d)) activities in the perfusate revealed similar trends, and the I/R effects were ameliorated by fisetin treatment. Similarly, the animals subjected to I/R exhibited decreases in the indices of hemodynamic parameters (Table 1) but showed improvement in cardiac function upon treatment with fisetin (Table 1).

3.2. Fisetin Mitigates Oxidative Stress in Mitochondria, Lysosomes, and Microsomes. In I/R-injured cardiac tissue, subcellular organelles undergo stress caused by the release of ROS from mitochondria. As mitochondria plays a major role in the I/R pathology, release of ROS can impair 
TABLE 1: Effect of fisetin on hemodynamic parameters.

\begin{tabular}{|c|c|c|c|c|c|}
\hline Group & $\begin{array}{c}\text { LVSP } \\
(\mathrm{mmHg})\end{array}$ & $\begin{array}{l}\text { LVDP } \\
(\mathrm{mmHg})\end{array}$ & $\begin{array}{c}\mathrm{RPP} \\
\left(\mathrm{mmHg}{ }^{*} \mathrm{BPM} \times 10^{3}\right)\end{array}$ & $\begin{array}{c}+\mathrm{dp} / \mathrm{dt} \\
(\mathrm{mmHg} / \mathrm{s})\end{array}$ & $\begin{array}{c}-\mathrm{dp} / \mathrm{dt} \\
(\mathrm{mmHg} / \mathrm{s})\end{array}$ \\
\hline Sham $(n=8)$ & $120.0 \pm 2.2$ & $13 \pm 1.3$ & $36.3 \pm 0.26$ & $3001.0 \pm 23.3$ & $3207.0 \pm 13.4$ \\
\hline Fisetin $+\operatorname{sham}(n=8)$ & $117.0 \pm 5.2$ & $12 \pm 2.2$ & $35.7 \pm 0.23$ & $2994.0 \pm 21.2$ & $3200.0 \pm 14.2$ \\
\hline $\mathrm{I} / \mathrm{R}(n=8)$ & $27.0 \pm 2.9^{*}$ & $16 \pm 3.1^{*}$ & $4.7 \pm 0.34^{*}$ & $1729.7 \pm 22.6^{*}$ & $1126.7 \pm 12.3^{*}$ \\
\hline Fisetin + I/R $(n=8)$ & $110.8 \pm 2.5^{\#}$ & $13 \pm 2.6^{\#}$ & $29.3 \pm 0.25^{\#}$ & $2842.0 \pm 26.9^{\#}$ & $2974.3 \pm 15.5^{\#}$ \\
\hline
\end{tabular}

LVSP: left ventricular systolic pressure; LVDP: left ventricular diastolic pressure; RPP: rate pressure product; $\pm \mathrm{dp} / \mathrm{dt}$ : ventricular contraction assessment. ${ }^{*} P<0.001$ versus sham/fisetin + sham; ${ }^{\#} P<0.01$ versus $\mathrm{I} / \mathrm{R}$.

autophagy by affecting the structure and function of lysosomes [30]. The endoplasmic reticulum which forms the major component of microsomes is equally affected by $I / R$ due to accumulation of unfolded proteins leading to loss of $\mathrm{Ca}^{2+}$ homeostasis in the myocardium. Hence, the restoration of autophagy and $\mathrm{Ca}^{2+}$ homeostasis and the reduction of ROS in the subcellular compartments are vital for the restoration of the normal cardiomyocyte function [30]. Therefore, we determined the oxidative stress markers such as the accumulation of lipid peroxides and endogenous antioxidants. As shown in Figure 2(a), the SOD activity was markedly reduced in all the subcellular compartments in myocardial tissues from the animals subjected to $I / R$. Likewise, the catalase (Figure 2(b)), GPx (Figure 2(e)), and GR (Figure 2(f)) activities were diminished in the animals subjected to the I/R procedure. The decrease in the endogenous antioxidant defense enzyme system corroborated a diminished GSH content (Figure 2(d)) and elevated accumulation of lipid peroxides (Figure 2(c)). However, fisetin treatment abrogated the oxidative stress and augmented the endogenous antioxidant defense system.

\subsection{Fisetin Attenuates I/R-Induced Disruption of} Mitochondrial ETC. The activities of NQR (Figure 3(a)), SQR (Figure 3(b)), SCCR (Figure 3(d)), QCCR (Figure 3(e)), and COX (Figure 3(f)) were markedly reduced in the mitochondria isolated from cardiac tissues obtained from the animals subjected to I/R. However, the NCCR activity was not affected by I/R. Moreover, fisetin treatment prevented the I/R-induced deterioration of ETC (Figure 3).

3.4. Fisetin Improves Mitochondrial Physiology. There was a marked generation of mitochondrial $\mathrm{O}_{2}{ }^{\bullet-}$ in the myocardial tissues obtained from the animals subjected to $\mathrm{I} / \mathrm{R}$ (Figure 4(a)). Similarly, mitochondrial swelling increased (Figure $4(\mathrm{~b})$ ) and the membrane potential was lost in the I/R subjected animals (Figure 4(c)). However, these effects were attenuated by fisetin treatment.

3.5. Fisetin Mitigates I/R-Induced Apoptosis. Loss of the mitochondrial membrane potential triggers the apoptosis cascade, which eventually results in the demise of cardiomyocytes. We observed a greater propensity for apoptosis in the I/R group, which was characterized by increased DNA fragmentation (Figure 5(a)) and elevated PARP and caspase 3 activities (Figures 5(b) and 5(c)). However, fisetin treatment blunted the I/R-induced apoptotic response in myocardial tissues.
3.6. Fisetin Augments Mitochondrial Biogenesis. First, we determined the impact of I/R on the mitochondrial histoarchitecture with the aid of transmission electron microscope. We observed that the induction of IRI resulted in interspersed vacuoles and a disarray of the myofibrillar lattice. Furthermore, mitochondria were markedly abnormal, with varying sizes and densities and characterized by a loss of the matrix and cristae (Figure 6(b)). However, fisetin treatment improved the mitochondrial histoarchitecture (Figure 6(c)). Next, we determined the mRNA expression of key meditators involved in the mitochondrial biogenesis. We observed that the gene expression of PGC1- $\alpha, N R F-1, N R F-2$, and TFAM was significantly diminished in myocardial tissues obtained from the animals subjected to the I/R procedure. However, fisetin treatment augmented the mitochondrial biogenesis, which was evident from the reversal of the mRNA expression levels of PGC1- $\alpha, N R F-1$, and TFAM (Figure 6(d)).

3.7. Fisetin Potently Inhibits GSK3 $\beta$ Activity. GSK3 $\beta$ activation has been reported to be associated with the defective mitochondrial physiology during cardiac I/R [31]. Therefore, there is immense interest in developing potent and selective inhibitors of GSK $3 \beta$, which could be used in the clinic to minimize IRI. Accordingly, we determined whether fisetin could inhibit the GSK $3 \beta$ activity in the myocardial tissues obtained from the I/R-subjected animals. The results showed that GSK3 $\beta$ was elevated in $\mathrm{I} / \mathrm{R}$ tissues but this increase was inhibited by fisetin (Figure 7). Based on this biochemical data, we performed a detailed bioinformatics analysis to characterize fisetin as a potent and selective inhibitor of GSK3 $\beta$.

3.8. In Silico Analysis to Characterize Fisetin as an Inhibitor of GSK $3 \beta$. We used the crystal structure of GSK3 $\beta$ (1Q41) as a template for modeling the GSK $3 \alpha$ structure. The sequence identity between GSK $3 \alpha$ and GSK $3 \beta$ is $77 \%$. The missing loops were modeled and refined. The modeled protein was subjected to a brief constrained energy minimization, and the calculated potential energy (OPLS3) of the modeled protein $(\mathrm{GSK} 3 \alpha)$ was $10,513 \mathrm{kcal} / \mathrm{mol}$. The calculated RMSD between the modeled GSK $3 \alpha$ and the GSK $3 \beta$ template was $0.92 \mathrm{~A}^{\circ}$ (Figure $8(\mathrm{a})$ ). The stereochemical quality of the model was evaluated using the Ramachandran plot (Figure $8(\mathrm{~b})$ ). Approximately $96.4 \%, 3.3 \%$, and $0.3 \%$ of the amino acids were present in the most favored, allowed, and outlier regions, respectively. The ERRAT value for all quality factors of the protein model was $88.21 \%$. The Verify3D results 


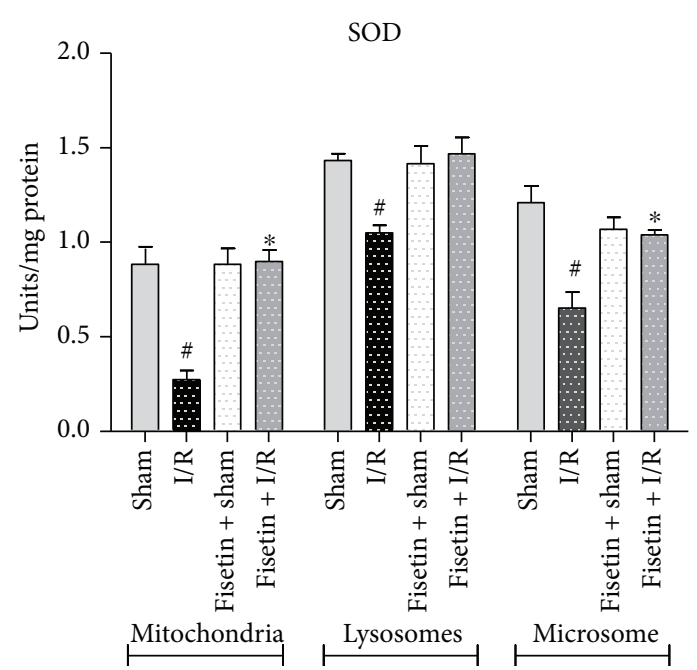

(a)

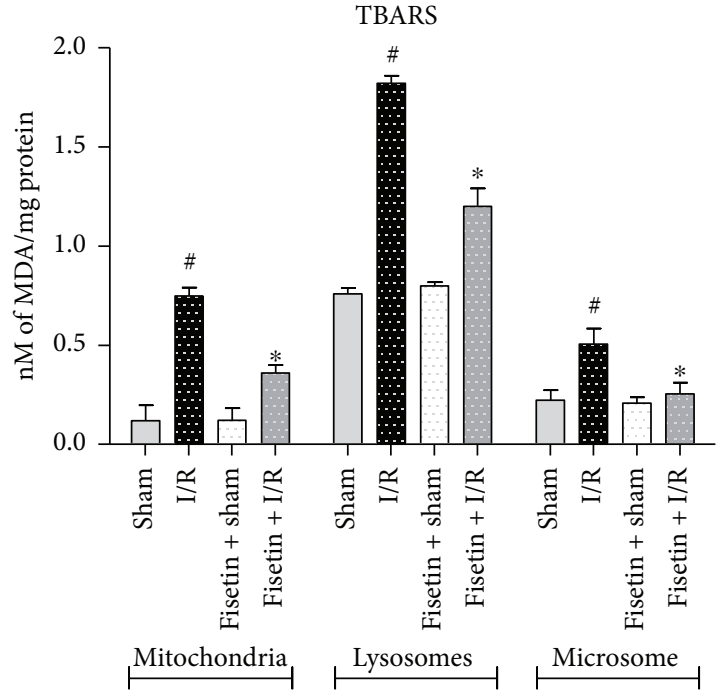

(c)

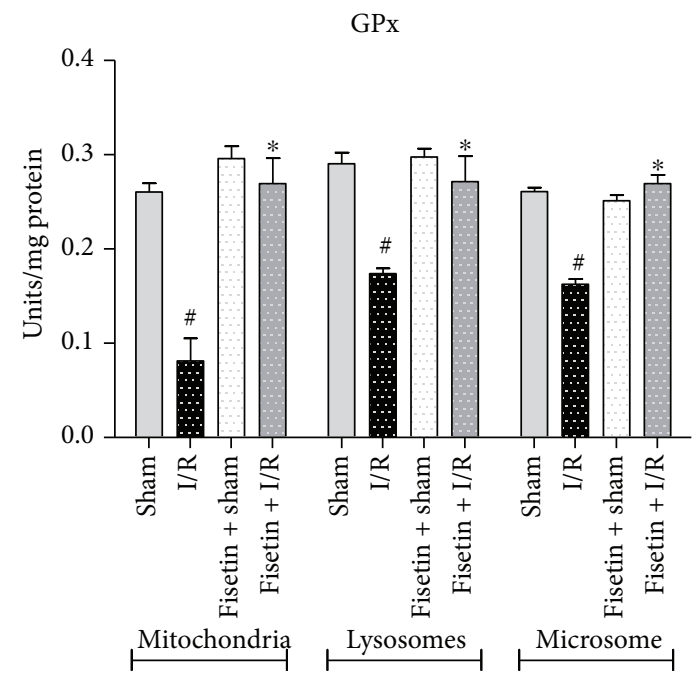

(e)

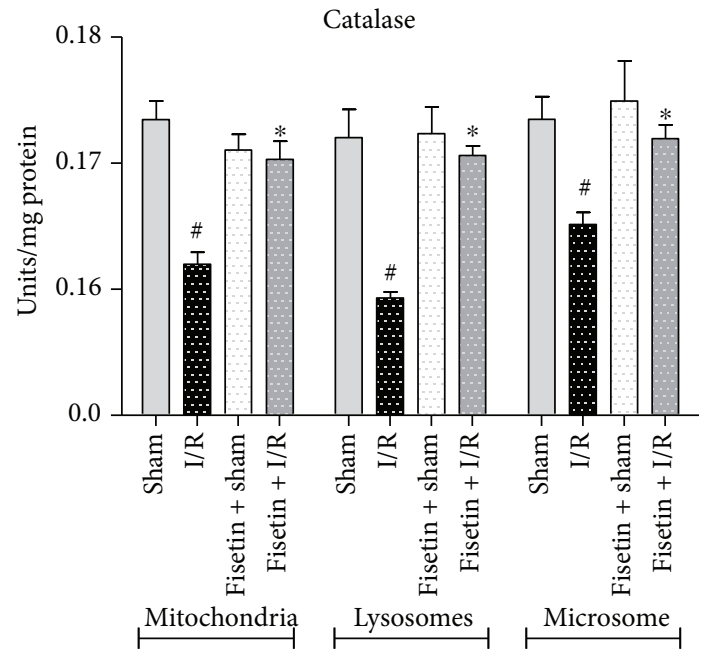

(b)

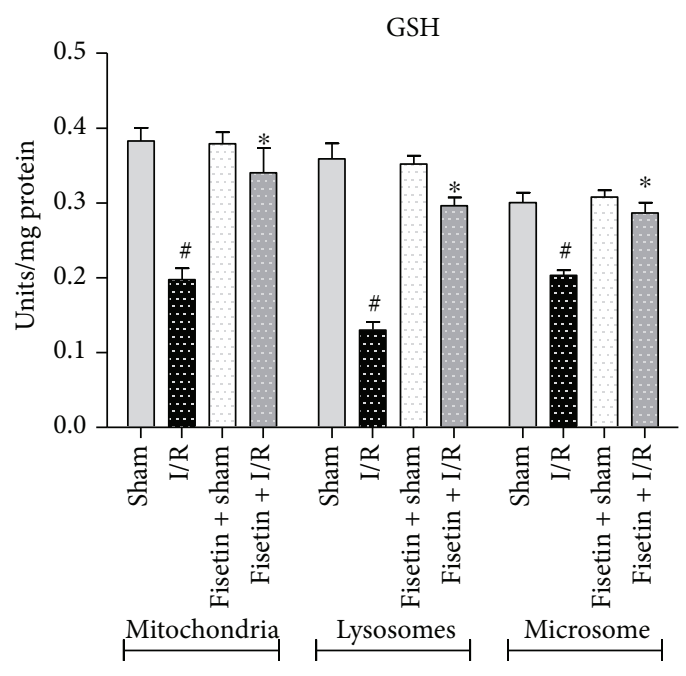

(d)

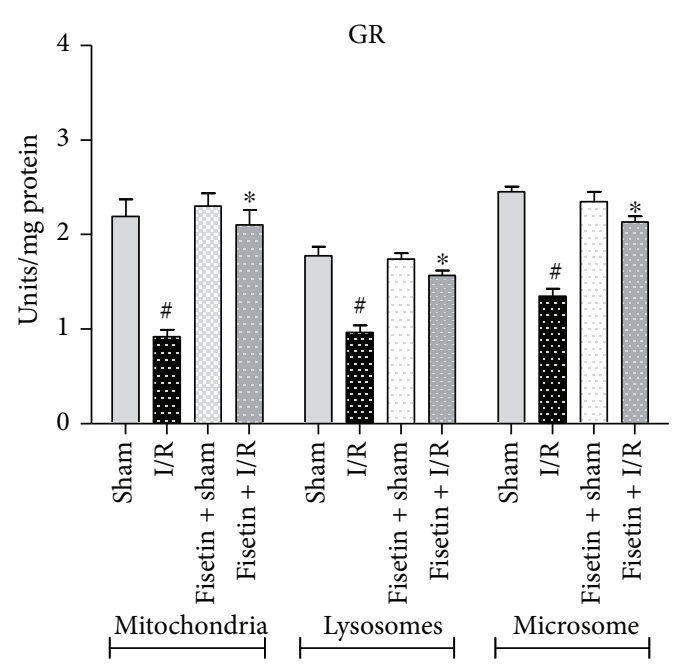

(f)

FIGURE 2: Effect of fisetin on subcellular antioxidant defense system isolated from heart tissues. (a) SOD activity, (b) catalase activity, (c) lipid peroxide accumulation, (d) total glutathione content, (e) GPx activity, and (f) GR activity in the respective groups. $n=6 /$ group; ${ }^{\#} P<0.001$ versus sham/sham \pm fisetin; ${ }^{*} P<0.01$ versus I/R. 


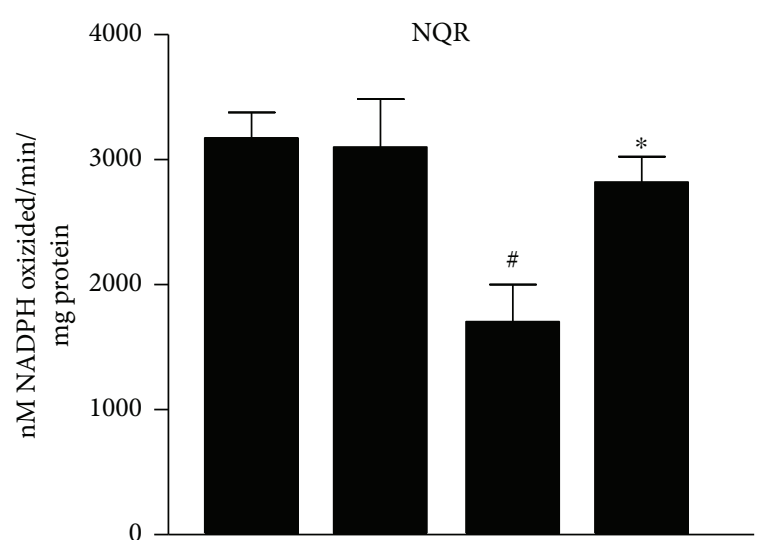

(a)

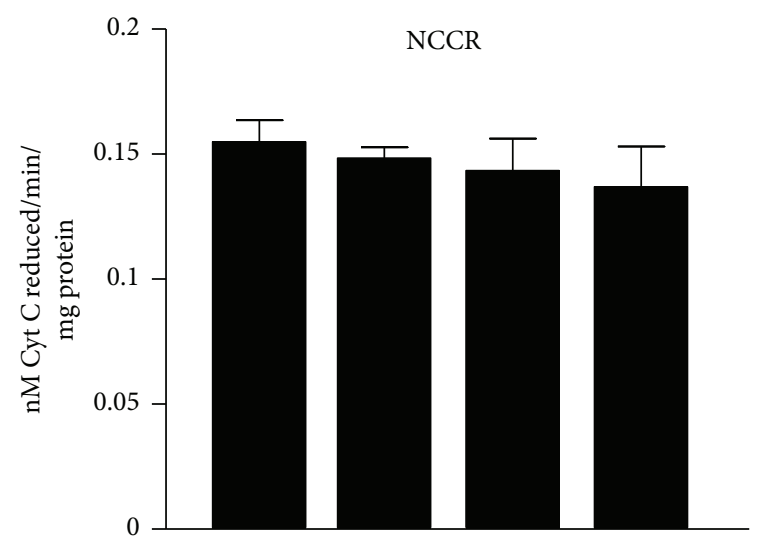

(c)

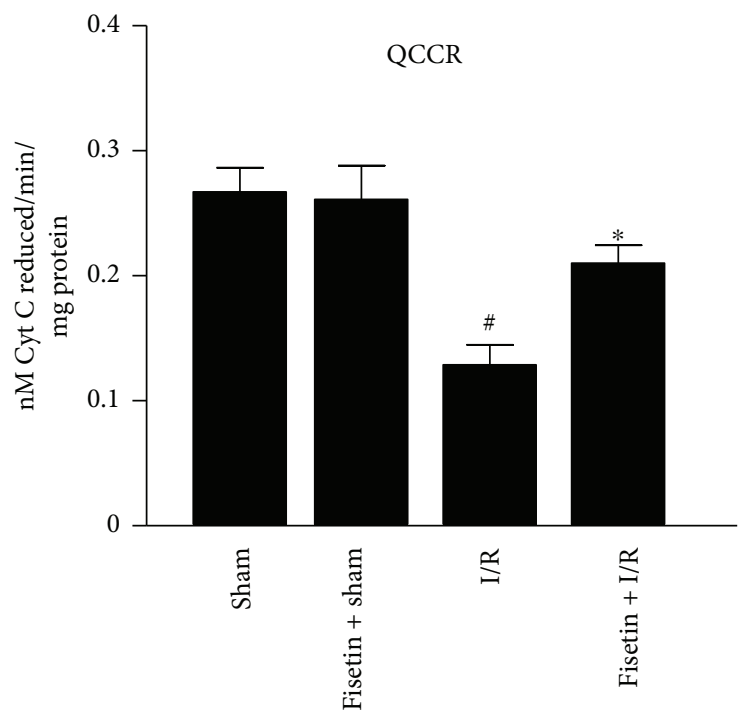

(e)

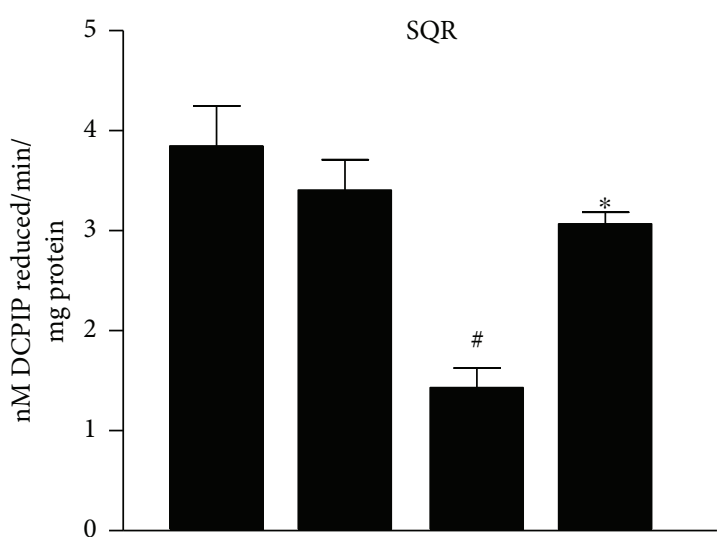

(b)

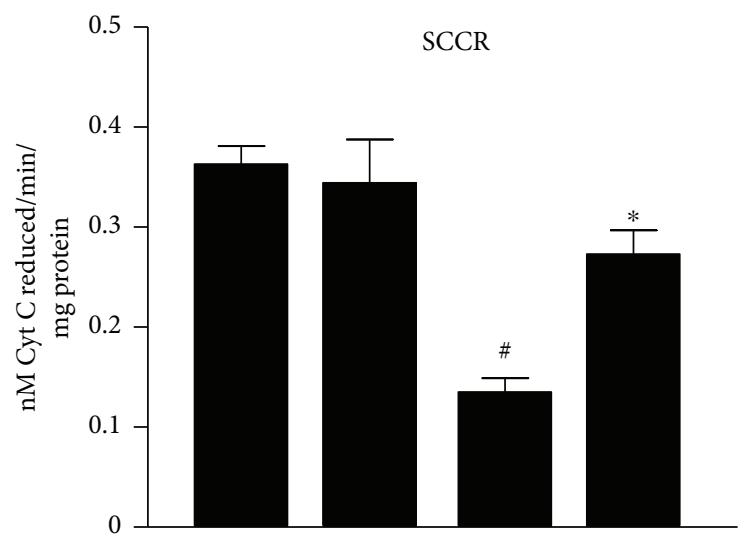

(d)

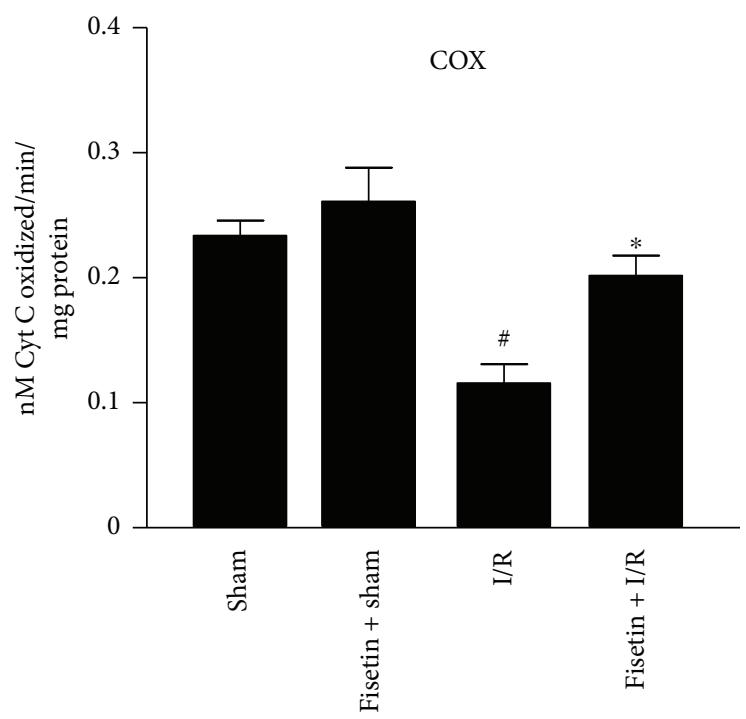

(f)

FIGURE 3: Effect of fisetin on mitochondrial enzyme activities. (a) NQR, (b) SQR, (c) NCCR, (d) SCCR, (e) QCCR, and (f) COX activities in the mitochondrial samples isolated from heart tissues. $n=6$ /group; ${ }^{\#} P<0.001$ versus sham $/$ sham \pm fisetin; ${ }^{*} P<0.01$ versus I/R.

showed that $89.09 \%$ of the residues had an average 3D-1D score of $\geq 0.2$ in the $3 \mathrm{D} / 1 \mathrm{D}$ profile. To evaluate the efficiency of the docking algorithm to reproduce the crystal pose, we removed indirubin- $3^{\prime}$-monoxime and redocked it using the Glide XP docking algorithm. The Glide docking algorithm was superior in reproducing the crystal pose as shown in (Figure 9(a)). Further Glide was used to dock fisetin into the binding site of GSK3 $\beta$ and GSK $3 \alpha$. The Glide docking score for the GSK3 $\beta$-fisetin complex was -10.067 and that for the GSK3 $\alpha$-fisetin complex was -6.40 . Glide 


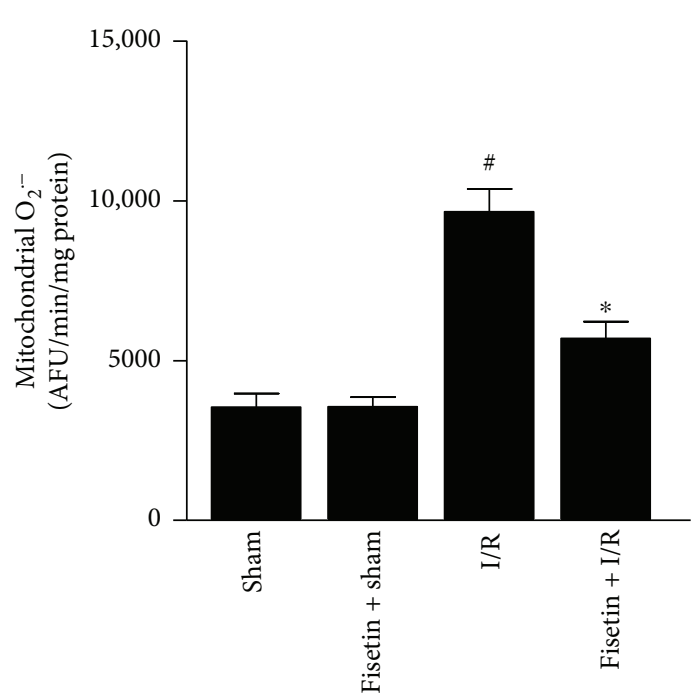

(a)

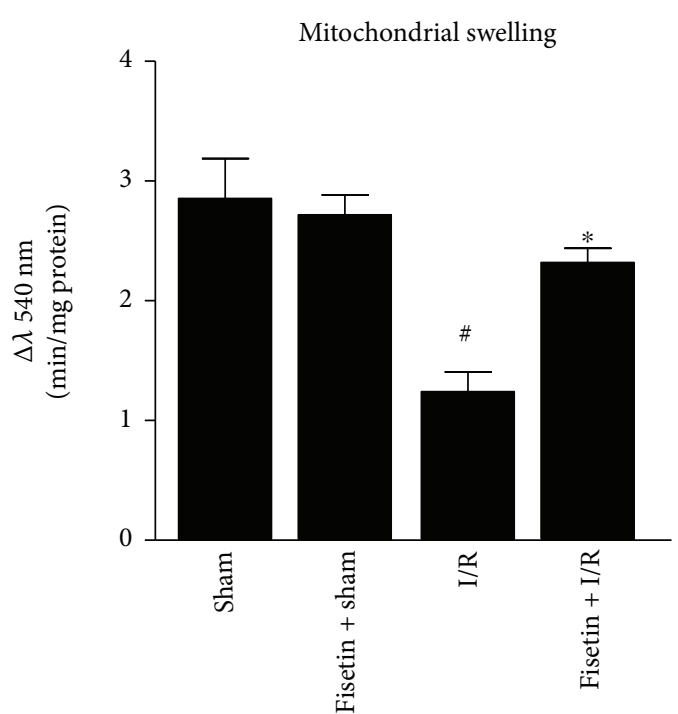

(b)

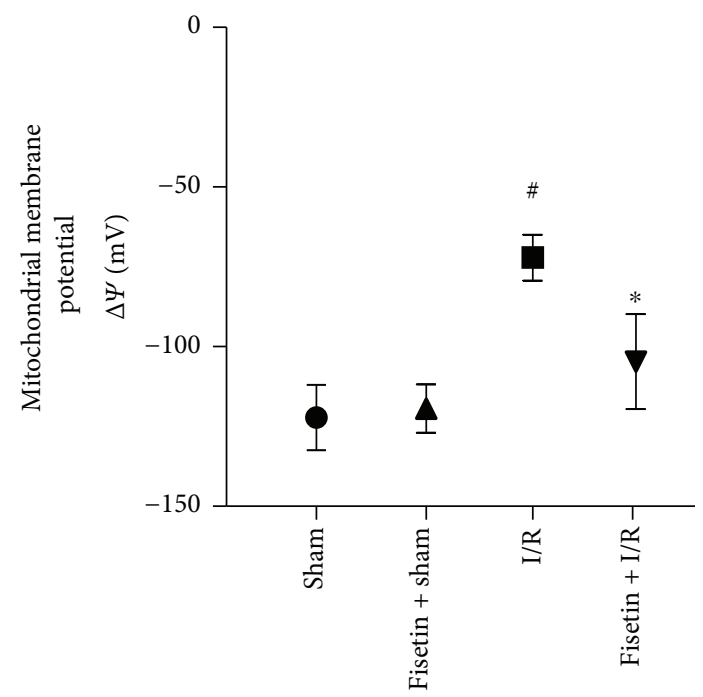

(c)

Figure 4: Effect of fisetin on mitochondrial physiology. (a) The mitochondrial superoxide generation, $n=6 /$ group; ${ }^{\#} P<0.001$ versus sham/ sham \pm fisetin; ${ }^{*} P<0.01$ versus I/R. (b) Mitochondrial swelling activity, $n=6 /$ group; ${ }^{\#} P<0.001$ versus sham/sham \pm fisetin; ${ }^{*} P<0.01$ versus I/R. (c) Mitochondrial membrane potential, $n=6$ /group; ${ }^{\#} P<0.01$ versus sham/sham \pm fisetin; ${ }^{*} P<0.05$ versus I/R.

score shows that fisetin has a higher affinity for the GSK3 $\beta$ than the GSK3 $\alpha$.

The docking analysis of the GSK3 $\beta$-fisetin complex revealed that fisetin formed three strong hydrogen bond interactions with the backbone of the amino acids Val135 and Gln185 (Figure 9(b)). In the case of GSK3 $\alpha$, fisetin was able to form hydrogen bond interaction with Ile 62, Glu133, Val135, and Asp200 (Figure 9(c)). The hydrogen bond interaction patterns observed in our docking study were consistent with the interactions observed in the crystal structures of various known GSK3 $\beta$-inhibitor complexes (PDB: 1PYX, 5HLN, 5HLP, 1Q41, and 3SAY) [32, 33]. Further analysis showed that the preferred orientations for fisetin binding to GSK $3 \alpha$ and GSK $3 \beta$ were completely different (Figures 9(b) and 9(c)). The docked pose of fisetin with GSK3 $\alpha$ showed that all the ring systems of the fisetin molecule were in the same plane and the dihydroxy phenyl group was projected away from the hinge region. However, with GSK3 $\beta$, the dihydroxy phenyl group of fisetin was slightly projected out of the plan and closer to the hinge region, and this conformation leads to the formation of hydrogen bonding with Gln185. This shows that the orientation of the dihydroxy phenyl ring of fisetin and its interactions with Gln185 could play a role in its affinity and selectivity. These analyses led to the conclusion that fisetin could be a potent and isoform-specific GSK3 $\beta$ inhibitor.

\section{Discussion}

Mitochondria are recognized as the primary target of the IRI in the myocardium. Timely reperfusion is performed to salvage the healthy myocardium after ischemic injury [34]. 


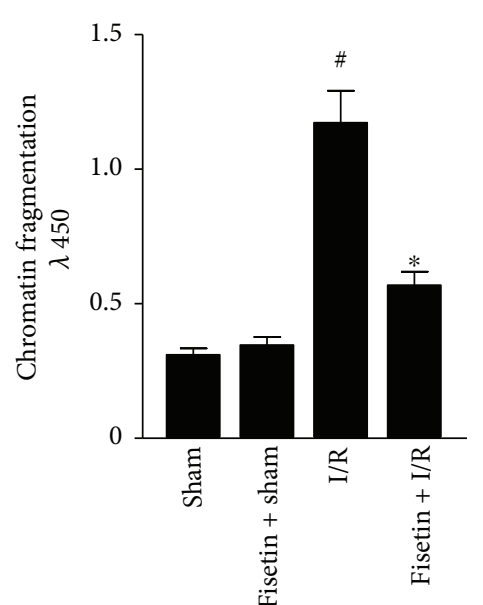

(a)

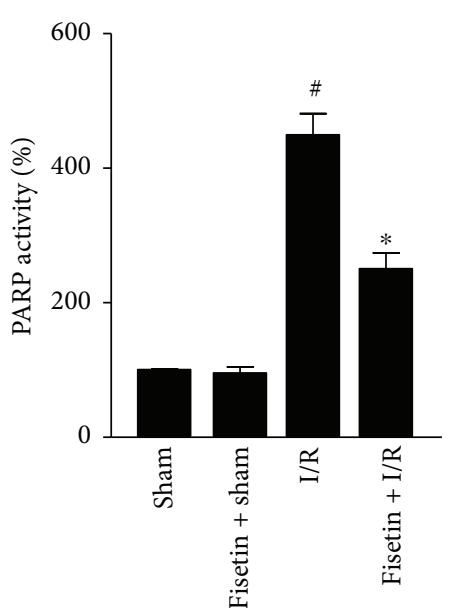

(b)

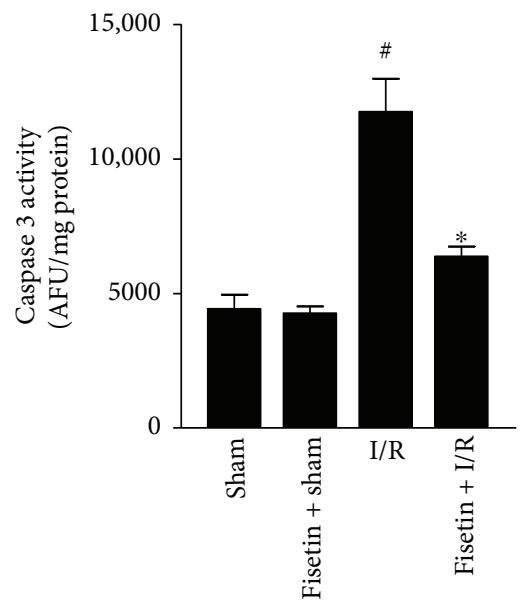

(c)

FIgURE 5: Effect of fisetin on myocardial apoptosis induced by IRI. (a) The DNA fragmentation, (b) PARP, and (c) caspase 3 activities in the heart tissues. $n=6$ /group; ${ }^{\#} P<0.001$ versus sham/sham \pm fisetin; ${ }^{*} P<0.01$ versus $\mathrm{I} / \mathrm{R}$.

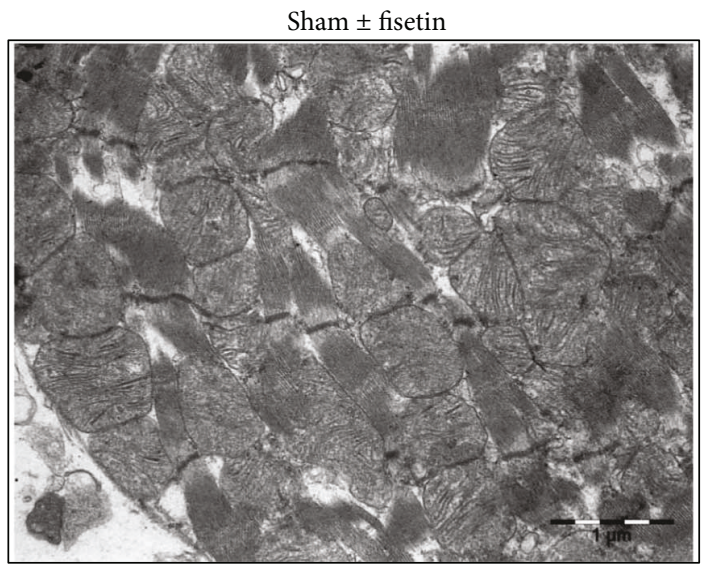

(a)

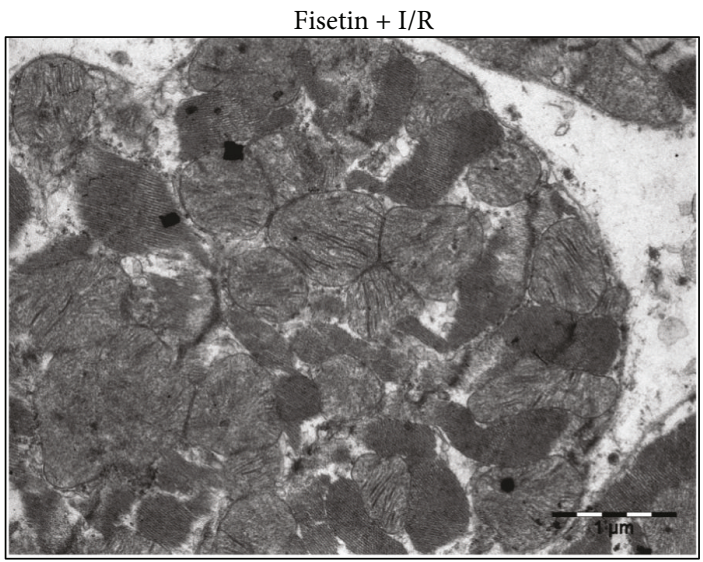

(c)

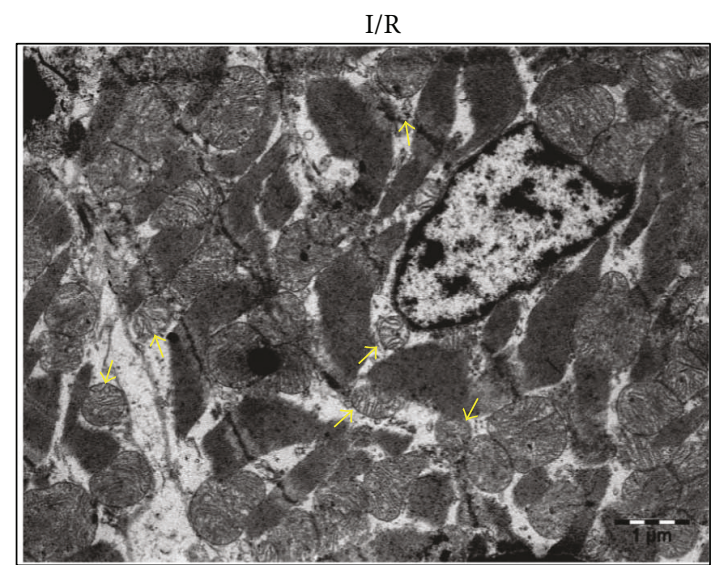

(b)

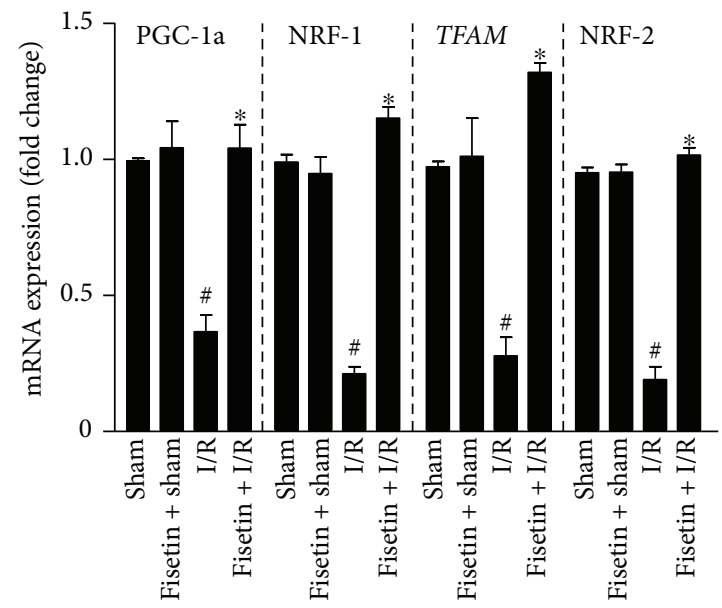

(d)

FIGURE 6: Effect of fisetin on myocardial tissue ultrastructure examined by electron microscope (EM) and mitochondrial biogenesis makers determined by qRT-PCR technique. (a) Representative EM picture of myocardial tissue processed from sham or sham \pm fisetin-treated animals. (b) Shown is the EM image of myocardial tissue from animals subjected to IRI; yellow arrowheads indicate that mitochondria are markedly abnormal, with varying size and densities and characterized by the loss of matrix and cristae. (c) EM picture reveals that fisetin attenuates mitochondrial damage induced by IRI. (d) The mRNA expression of mitochondria biogenesis markers; $n=6 /$ group; ${ }^{\#} P<0.001$ versus sham/sham \pm fisetin; ${ }^{*} P<0.01$ versus I/R. 


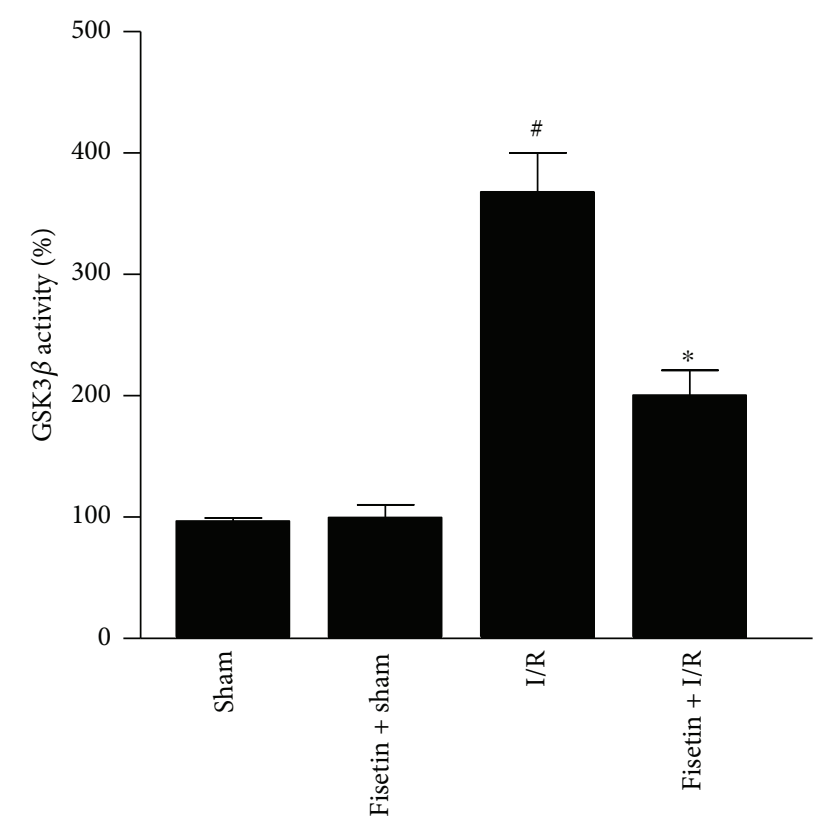

FIGURE 7: Fisetin inhibits GSK3 $\beta$ activity in myocardial IRI tissues; $n=6 /$ group; ${ }^{\#} P<0.001$ versus sham/sham \pm fisetin; ${ }^{*} P<0.01$ versus I/R.

Efforts to unravel the potential pathomechanisms of IRI are restrained because of the lack of a bonafide biomarker and definitive clinical endpoints. During IRI, the damage to the mitochondrial ETC chiefly occurs during the ischemic phase [35]. The reperfusion phase exacerbates the injury in the myocardium, which occurs during the previous phase of ischemic insult, and this drives an excessive ROS production and perturbation of $\mathrm{Ca}^{2+}$ homeostasis, resulting in abnormal mitochondrial membrane permeability and increased swelling [36]. Furthermore, increased mitochondrial ROS production can result in decreased oxidative phosphorylation and can jeopardize the functional recovery of the ailing myocardium after IRI. It is pertinent to note that the adequate supply of ATP is crucial for augmenting the metabolic activity, aiding in collateral circulation (neoangiogenesis), which is of paramount significance for improving the cardiac function [37].

In the present study, we observed significant myocardial tissue injury in animals subjected to myocardial IRI, as revealed by compromised cardiac function. However, when animals were pretreated with fisetin, there was a marked improvement in cardiac function and decrease of myocyte injury markers such as LDH and CK. Prior studies have reported that fisetin showed antioxidant activity and ameliorated various inflammatory diseases in preclinical studies [38-40].

Mitochondrial permeability transition pore (mPTP) opening results in destabilization of mitochondrial membrane integrity, and this leads to the extrusion of ionic contents [41]. Maintenance of mitochondria health during I/R plays a key role in the recovery of myocardium. Especially, the opening of mPTP during early stage of reperfusion injury is shown to increase the myocardial infarct size and the drugs inhibiting $\mathrm{MPTP}$ opening can provide cardioprotection by preserving mitochondrial structure and function [42]. mPTP is shown to mediate the apoptosis by rendering the pore permeable to molecule release from the matrix to the cytosol, thereby disrupting the membrane potential and uncoupling the oxidative phosphorylation. Therefore, to assess the effect of fisetin on the mPTP opening, we measured the $\mathrm{Ca}^{2+}$ induced swelling behavior due to the I/R in the mitochondria isolated from the heart tissues. Our results indicated impaired swelling behavior due to I/R which was improved in samples obtained from fisetin-pretreated animals. In addition, we observed that membrane potential $(\Delta \psi \mathrm{mV})$ in fisetin $+\mathrm{I} / \mathrm{R}$ group remained hyperpolarized, compared to I/R group. These observations suggest that fisetin inhibits mPTP opening and improves the mitochondrial function, thereby preventing I/R-induced myocardial tissue injury. Our findings are in agreement with a previous study, which demonstrated that fisetin could counteract oxidative stressinduced renal tissue damage by improving the oxidative phosphorylation and improving the mitochondrial complex activities [43].

Because of the restricted rate of cardiomyocyte renewal following cardiomyocyte death, in both the injured and adjacent area upon IRI, the adult heart is unable to restore the damaged tissue upon myocardial infarction [44]. Instead, scar formation is induced in the damaged zone resulting in a loss of contractility rather than in myocardial tissue repair. Moreover, the myocardial tissue ceaselessly functions to provide ATP and regulate the metabolic tone of the heart, which has one of the highest oxygen consumption rates in the body, mostly through aerobic metabolism [45]. Since cardiomyocytes are terminally differentiated, they cannot be easily replenished. Therefore, cardiomyocytes are sensitive to any abnormal stress or stimuli, and consequently, an efficient antioxidant defense system is vital for the prevention IRI-induced damage to cardiomyocytes. During IRI, ROS accumulation over time overpowers the antioxidant capacity of mitochondria, which is primarily provided by SOD, catalase, GPx, and GR. When the antioxidant rheostat malfunctions during IRI, this culminates in mitochondrial dysfunction and subsequently affects the cardiac function [4]. In this study, we observed that fisetin treatment could potentially save the mitochondria from IRI by bolstering their antioxidant capacity.

Cardiac myocytes undergo profound age-related alterations which are necessary for the sustenance and survival during the lifespan of an individual. Autophagy (self-cannibalism) is a mechanism employed by cardiomyocytes for their survival under physiological and pathological conditions [30]. It has been reported that the accumulation of defective autophagosomes are associated with the pathogenesis of several cardiovascular diseases, including IRI [30]. Defective autophagosomes can contain damaged mitochondria, unfolded protein aggregates, and other globular complex lipid-protein complexes [30]. Under physiological conditions, cardiomyocyte lysosomes contain digestive enzymes such as calpain, which process these cellular waste products [46]. However, during I/R, the mitochondria swell due to dysfunctional mPTP that leads to recruitment of Parkin, which activates calpain-1 and promotes autophagy. 


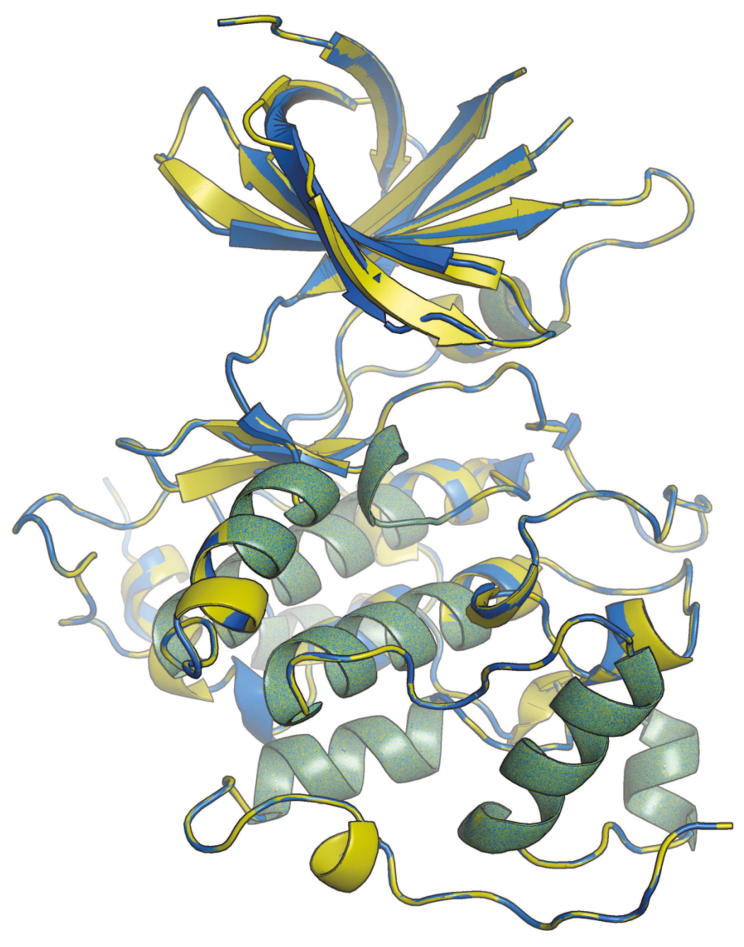

(a)

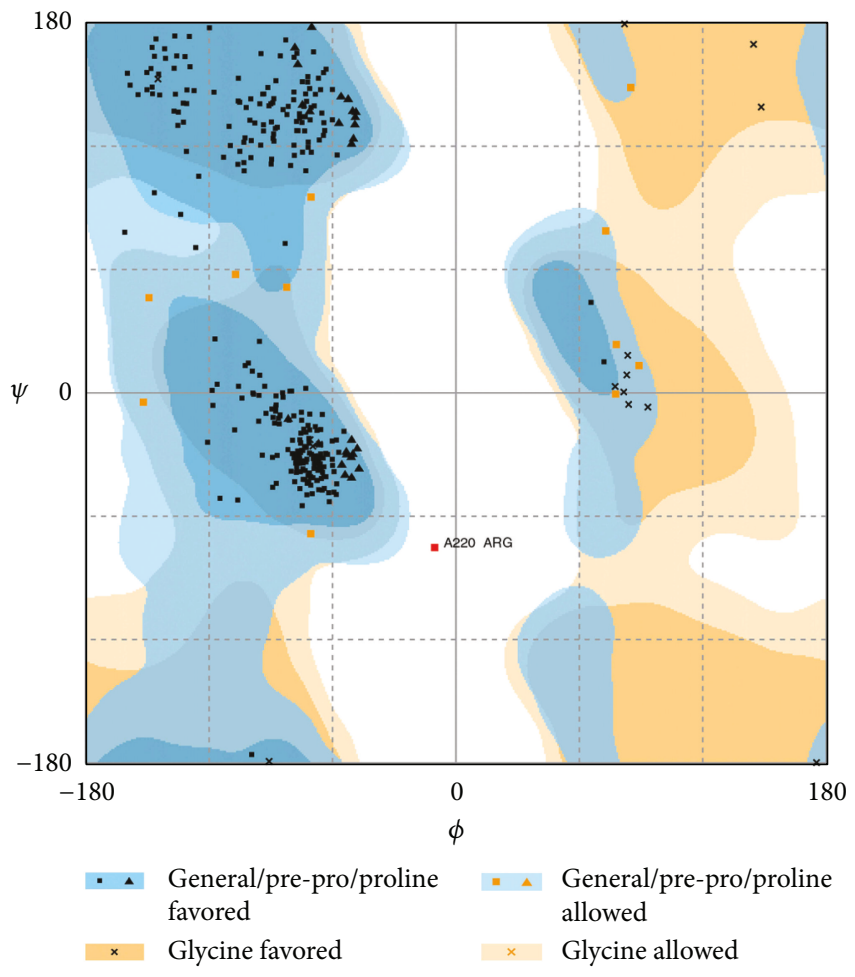

(b)

FIGURE 8: Comparative modeling of GSK3 $\alpha$ using the crystal structure of GSK3 $\beta$ (PDB: 1Q41). (a) Molecular superimposition of GSK3 $\alpha$ and GSK3 $\beta$. Crystal structure of GSK3 $\beta$ and modeled GSK3 $\alpha$ were shown in blue and yellow. (b) Ramachandran plot of the modeled GSK3 $\alpha$.

Furthermore, these events are fueled by vicious cycle of increased ROS generation that culminates in the heart failure $[46,47]$. Similarly, a premature rupture of lysosomes releases a labile iron pool from hydrolytic enzymes, which perpetuates Fenton's reaction and propagation of oxidative stress, which in turn inflicts lysosomal injury through oxidative modification of lipids and proteins [48].

Therefore, stable lysosomes are vital for the sustenance of healthy cardiomyocytes and their protection from deleterious effects of IRI [49]. In this regard, the effective antioxidant capacity is vital for the prevention of lysosome destabilization during IRI [49]. In our present study, we observed that lysosomes and microsomes obtained from IRI-affected hearts exhibited exaggerated oxidative stress, characterized by diminished levels of endogenous antioxidants and accumulation of lipid peroxides. However, treatment with fisetin blunted the oxidative stress and this effect corroborated with the improved cardiac function. Additionally, previous studies have reported that fisetin significantly attenuated rotenone-induced neuroinflammation, by scavenging ROS at mitochondria. In fact, previous studies have documented that fisetin could engage NRF-2 and augment the expression of hemooxugenase-1 (HO-1) as well as confer protection against oxidative insult in human endothelial cells [50].

Apoptotic cell death is the key feature of I/R-induced myocardial tissue injury and heart failure. Previous studies have reported that the treatment with natural or synthetic antioxidants could be beneficial in thwarting the IRIinduced myocardial tissue injury [5]. Herein, we have observed that IRI-affected heart tissues exhibited increased DNA fragmentation, which was accompanied by increased PARP and caspase 3 activities, signifying an increased rate of apoptosis. Remarkably, fisetin treatment blunted the apoptotic response in agreement with a previous report showing that fisetin elicited an antiapoptotic effect during inflammatory stress [51].

Mitochondrial biogenesis is a process of the replenishment of damaged/defective mitochondria in cells, and this phenomenon is universally observed in most cells and tissues [52]. It is pertinent to note that defective mitochondrial biogenesis has been reported in myocardial IRI and other cardiovascular diseases [53]. Therefore, defective mitochondrial biogenesis in cardiomyocytes during IRI could hamper myocardial recovery and eventually result in heart failure [53]. In our present study, we observed that mRNA expression of key transcription factors regulating mitochondrial biogenesis such as PGC-1 $\alpha, N R F-1$, and TFAM was reduced in the hearts obtained from IRI animals. However, mitochondrial biogenesis improved when the animals were treated with fisetin. Previous studies have reported that fisetin could augment the mitochondrial biogenesis in adipocytes via PGC- $1 \alpha$ activation, and our present findings are consistent with these observations [54].

GSK3 $\beta$ is a serine/threonine kinase playing a pivotal role during development, cell proliferation, migration, differentiation, modulation of apoptosis, and oncogenesis [55]. Previous studies have indicated that inhibition of the GSK3 $\beta$ activity could confer cardioprotection against IRI [9]. GSK3 $\beta$ 


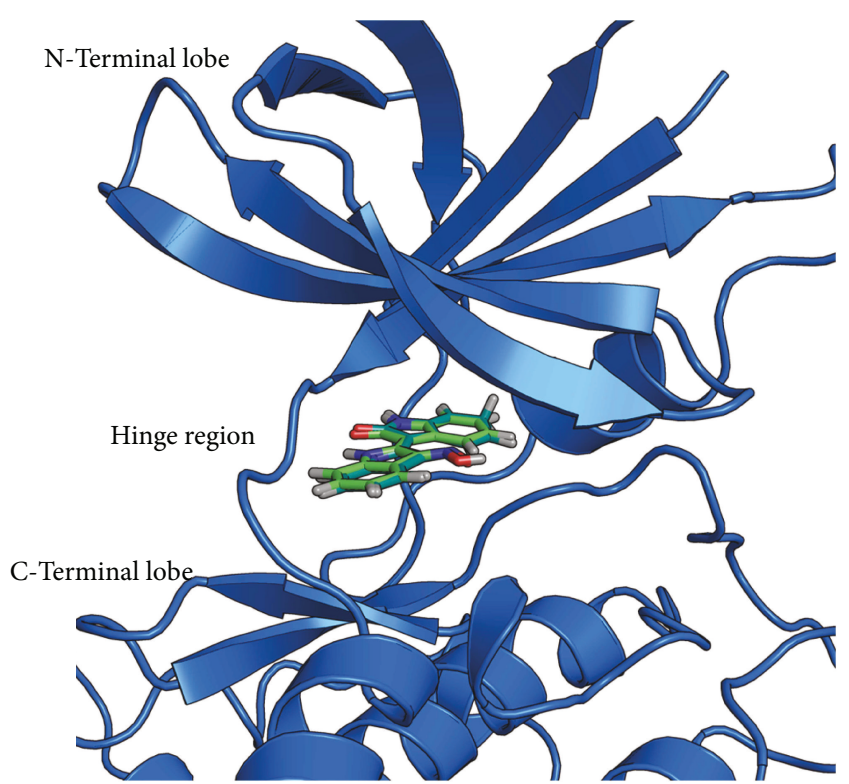

(a)

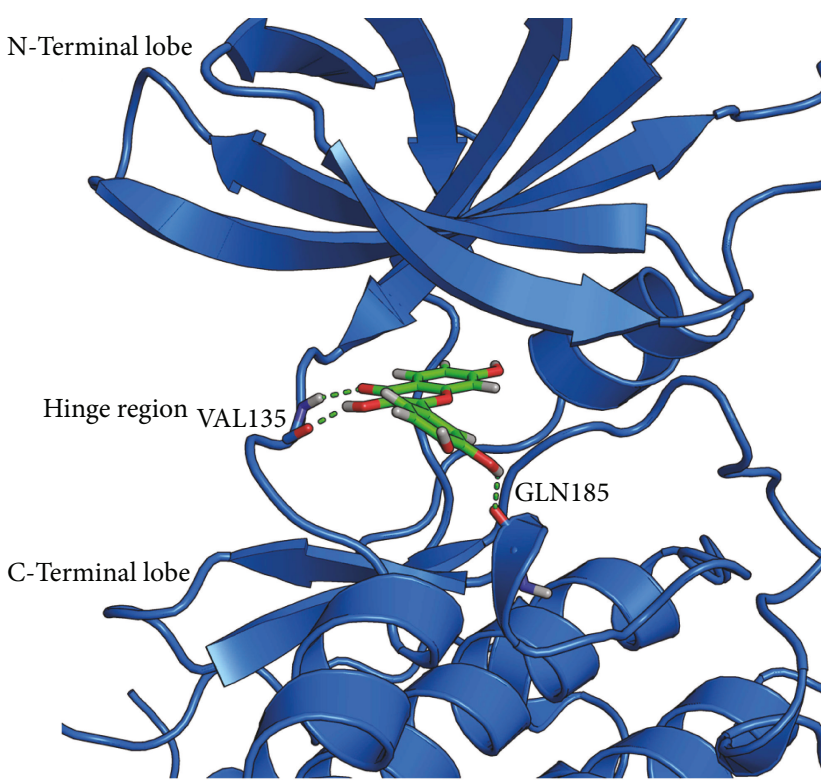

(b)

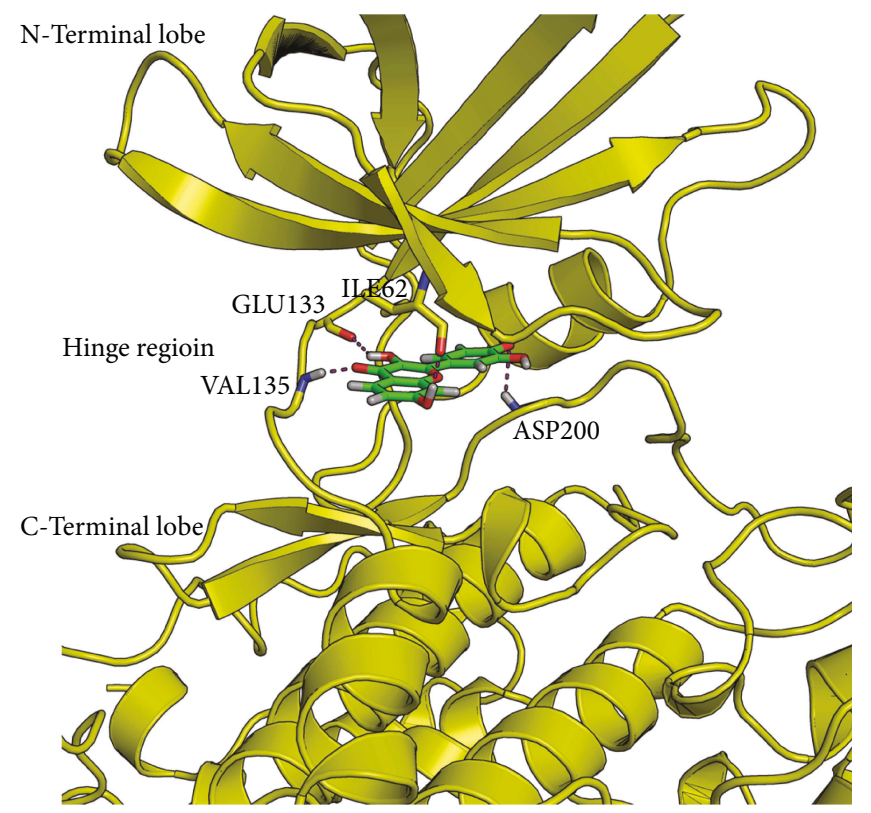

(c)

FIgURE 9: Molecular docking and hydrogen bonding interactions. (a) Molecular redocking of indirubin- $3^{\prime}$-monoxime with GSK3 $\beta$. The crystal and redocked poses are shown in green and blue, respectively. (b) Molecular docking and hydrogen bonding interactions of fisetin with GSK3 $\alpha$. Hydrogen bonding interaction is shown as dotted green lines. (c) Molecular docking and hydrogen bond interactions of fisetin with GSK3 $\beta$. Hydrogen bond interactions are shown as dotted red lines.

has been reported to regulate PGC- $1 \alpha$ degradation. GSK3 $\beta$ represses the PGC- $1 \alpha$ activation, through phosphorylation and thus priming PGC- $1 \alpha$ for degradation via the ubiquitin-proteasome pathway [56]. Inhibition of GSK3 $\beta$ promotes the mitochondrial biogenesis during ischemia cerebral injury [57]. Moreover, defective GSK3 $\beta$ activity is linked to dysregulated mitochondrial biogenesis [56]. Therefore, we determined the GSK $3 \beta$ activity in myocardial tissues obtained from respective groups of mice and found that GSK3 $\beta$ activity was significantly increased in the samples from IRI group, but the increase was suppressed by fisetin treatment. Moreover, it is pertinent to note that fisetin has been reported to attenuate the GSK $3 \beta$ activity in vivo during neuroinflammatory insult in preclinical studies [58]. Therefore, it is likely that fisetin could recruit PGC- $1 \alpha$, augment the mitochondrial biogenesis, repress the mitochondrial oxidative stress, and ameliorate the myocardial IRI. To further confirm our in vivo findings, in silico molecular docking studies were performed to ascertain whether fisetin could serve as a selective and potent inhibitor of GSK3 $\beta$ activity. Our results suggested that the compound could selectively inhibit the GSK $3 \beta$ activity. 


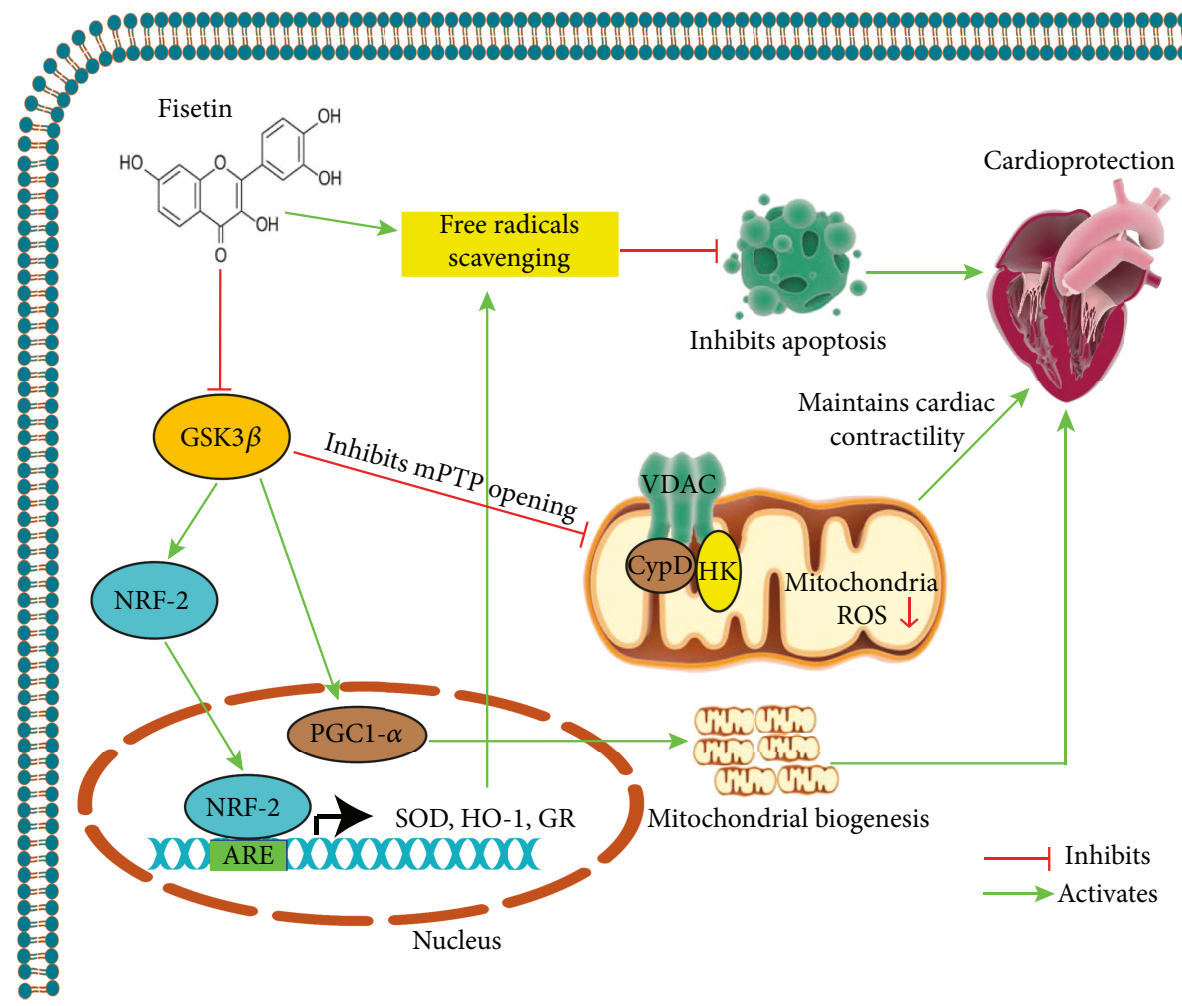

FIGURE 10: This scheme shows the fisetin cardioprotective effects against myocardial tissue injury upon I/R. Fisetin scavenges ROS and prevents mitochondrial dysfunction by inducing the Nrf-1/2 expression, bolstering the mitochondrial physiology, and inhibiting the GSK $3 \beta$ activity.

In summary, our definitive and novel findings obtained in this study indicate that fisetin confers cardioprotection against myocardial IRI, by bolstering the mitochondrial physiology, suppressing the oxidative stress, and augmenting the mitochondrial biogenesis, and these effects are mediated via inhibition of GSK3 $\beta$ activity (Figure 10). Since fisetin is well tolerated in human subjects and does not show toxic effects, this natural small molecule has bright prospects for further pharmaceutical development to be used against I/R-induced myocardial tissue injury and potentially for the treatment of cardiovascular diseases.

\section{Conflicts of Interest}

The authors report no conflict of interest.

\section{Authors' Contributions}

All authors participated in the study design. Sriram Ravindran and Karthi Shanmugam performed the experiments and collected and analyzed the data. Mohanraj Rajesh provided novel reagents and kits for the study. Mohanraj Rajesh and Gino A. Kurian supervised the study. Mohanraj Rajesh performed the literature search, drafted, edited, and prepared the final version of the manuscript. Gino A. Kurian edited the manuscript. Karthi Shanmugam and Sriram Ravindran contributed equally to this work.

\section{Acknowledgments}

This study was supported in part by intramural research grants funded by the College of Medicine and Health Sciences and College of Graduate Studies and Office of Sponsored Research of United Arab Emirates University (Mohanraj Rajesh). Gino A. Kurian received a grant from the Department of Science and Technology, Government of India, to procure research equipments (5/4/1-14/12NCD-II). The authors thank the Cancer Institute, Chennai, India, for their assistance with the use of the electron microscope facility.

\section{References}

[1] E. Braunwald and R. A. Kloner, "Myocardial reperfusion: a double-edged sword?," The Journal of Clinical Investigation, vol. 76, no. 5, pp. 1713-1719, 1985.

[2] K. Thygesen, J. S. Alpert, A. S. Jaffe et al., "Third universal definition of myocardial infarction," Journal of the American College of Cardiology, vol. 60, no. 16, pp. 1581-1598, 2012.

[3] D. J. Hausenloy and D. M. Yellon, "Myocardial ischemiareperfusion injury: a neglected therapeutic target," The Journal of Clinical Investigation, vol. 123, no. 1, pp. 92-100, 2013.

[4] A. E. Consolini, M. I. Ragone, P. Bonazzola, and G. A. Colareda, "Mitochondrial bioenergetics during ischemia and reperfusion," Advances in Experimental Medicine and Biology, vol. 982, pp. 141-167, 2017.

[5] G. A. Kurian, R. Rajagopal, S. Vedantham, and M. Rajesh, "The role of oxidative stress in myocardial ischemia and 
reperfusion injury and remodeling: revisited," Oxidative Medicine and Cellular Longevity, vol. 2016, Article ID 1656450, 14 pages, 2016.

[6] G. Bjorklund, M. Dadar, S. Chirumbolo, and R. Lysiuk, "Flavonoids as detoxifying and pro-survival agents: what's new?," Food and Chemical Toxicology, vol. 110, pp. 240-250, 2017.

[7] P. H. Sugden, S. J. Fuller, S. C. Weiss, and A. Clerk, "Glycogen synthase kinase 3 (GSK3) in the heart: a point of integration in hypertrophic signalling and a therapeutic target? A critical analysis," British Journal of Pharmacology, vol. 153, no. S1, pp. S137-S153, 2008.

[8] M. Juhaszova, D. B. Zorov, S. H. Kim et al., "Glycogen synthase kinase- $3 \beta$ mediates convergence of protection signaling to inhibit the mitochondrial permeability transition pore," The Journal of Clinical Investigation, vol. 113, no. 11, pp. 15351549, 2004.

[9] M. Juhaszova, D. B. Zorov, Y. Yaniv, H. B. Nuss, S. Wang, and S. J. Sollott, "Role of glycogen synthase kinase- $3 \beta$ in cardioprotection," Circulation Research, vol. 104, no. 11, pp. 1240-1252, 2009.

[10] C. Wagner, D. Tillack, G. Simonis, R. H. Strasser, and C. Weinbrenner, "Ischemic post-conditioning reduces infarct size of the in vivo rat heart: role of PI3-K, mTOR, GSK-3 $\beta$, and apoptosis," Molecular and Cellular Biochemistry, vol. 339, no. 1-2, pp. 135-147, 2010.

[11] N. Khan, D. N. Syed, N. Ahmad, and H. Mukhtar, "Fisetin: a dietary antioxidant for health promotion," Antioxidants \& Redox Signaling, vol. 19, no. 2, pp. 151-162, 2013.

[12] S. Ravindran, S. Jahir Hussain, S. R. Boovarahan, and G. A. Kurian, "Sodium thiosulfate post-conditioning protects rat hearts against ischemia reperfusion injury via reduction of apoptosis and oxidative stress," Chemico-Biological Interactions, vol. 274, pp. 24-34, 2017.

[13] S. Ravindran, J. Murali, S. K. Amirthalingam, S. Gopalakrishnan, and G. A. Kurian, "Vascular calcification abrogates the nicorandil mediated cardio-protection in ischemia reperfusion injury of rat heart," Vascular Pharmacology, vol. 89, pp. 31-38, 2017.

[14] S. Ravindran, S. R. Boovarahan, K. Shanmugam, R. C. Vedarathinam, and G. A. Kurian, "Sodium thiosulfate preconditioning ameliorates ischemia/reperfusion injury in rat hearts via reduction of oxidative stress and apoptosis," Cardiovascular Drugs and Therapy, vol. 31, no. 5-6, pp. 511-524, 2017.

[15] S. Ravindran, S. Ansari Banu, and G. A. Kurian, "Hydrogen sulfide preconditioning shows differential protection towards interfibrillar and subsarcolemmal mitochondria from isolated rat heart subjected to revascularization injury," Cardiovascular Pathology, vol. 25, no. 4, pp. 306-315, 2016.

[16] J. M. Graham, "Preparation of crude subcellular fractions by differential centrifugation," TheScientificWorldJOURNAL, vol. 2, pp. 1638-1642, 2002.

[17] U. Michelsen and J. von Hagen, "Isolation of subcellular organelles and structures," Methods in Enzymology, vol. 463, pp. 305-328, 2009.

[18] H. Ohkawa, N. Ohishi, and K. Yagi, "Assay for lipid peroxides in animal tissues by thiobarbituric acid reaction," Analytical Biochemistry, vol. 95, no. 2, pp. 351-358, 1979.

[19] J. Sedlak and R. H. Lindsay, "Estimation of total, proteinbound, and nonprotein sulfhydryl groups in tissue with Ellman's reagent," Analytical Biochemistry, vol. 25, no. 1, pp. 192-205, 1968.
[20] M. E. Martens, C. H. Chang, and C. P. Lee, "Reye's syndrome: mitochondrial swelling and $\mathrm{Ca}^{2+}$ release induced by Reye's plasma, allantoin, and salicylate," Archives of Biochemistry and Biophysics, vol. 244, no. 2, pp. 773-786, 1986.

[21] R. C. Scaduto Jr. and L. W. Grotyohann, "Measurement of mitochondrial membrane potential using fluorescent rhodamine derivatives," Biophysical Journal, vol. 76, no. 1, pp. 469-477, 1999.

[22] P. Back, F. Matthijssens, J. R. Vanfleteren, and B. P. Braeckman, "A simplified hydroethidine method for fast and accurate detection of superoxide production in isolated mitochondria," Analytical Biochemistry, vol. 423, no. 1, pp. 147-151, 2012.

[23] M. Rajesh, S. Batkai, M. Kechrid et al., "Cannabinoid 1 receptor promotes cardiac dysfunction, oxidative stress, inflammation, and fibrosis in diabetic cardiomyopathy," Diabetes, vol. 61, no. 3, pp. 716-727, 2012.

[24] M. Rajesh, P. Mukhopadhyay, S. Batkai et al., "Cannabidiol attenuates cardiac dysfunction, oxidative stress, fibrosis, and inflammatory and cell death signaling pathways in diabetic cardiomyopathy," Journal of the American College of Cardiology, vol. 56, no. 25, pp. 2115-2125, 2010.

[25] M.-Y. Shen and A. Sali, "Statistical potential for assessment and prediction of protein structures," Protein Science, vol. 15, no. 11, pp. 2507-2524, 2006.

[26] J. U. Bowie, R. Luthy, and D. Eisenberg, “A method to identify protein sequences that fold into a known three-dimensional structure," Science, vol. 253, no. 5016, pp. 164-170, 1991.

[27] H. M. Berman, J. Westbrook, Z. Feng et al., "The Protein Data Bank," Nucleic Acids Research, vol. 28, no. 1, pp. 235-242, 2000.

[28] G. Madhavi Sastry, M. Adzhigirey, T. Day, R. Annabhimoju, and W. Sherman, "Protein and ligand preparation: parameters, protocols, and influence on virtual screening enrichments," Journal of Computer-Aided Molecular Design, vol. 27, no. 3, pp. 221-234, 2013.

[29] R. A. Friesner, J. L. Banks, R. B. Murphy et al., "Glide: a new approach for rapid, accurate docking and scoring. 1. Method and assessment of docking accuracy," Journal of Medicinal Chemistry, vol. 47, no. 7, pp. 1739-1749, 2004.

[30] Y. Matsui, S. Kyoi, H. Takagi et al., "Molecular mechanisms and physiological significance of autophagy during myocardial ischemia and reperfusion," Autophagy, vol. 4, no. 4, pp. 409415, 2008.

[31] T. Miura and M. Tanno, "Mitochondria and GSK-3 $\beta$ in cardioprotection against ischemia/reperfusion injury," Cardiovascular Drugs and Therapy, vol. 24, no. 3, pp. 255-263, 2010.

[32] J. A. Bertrand, S. Thieffine, A. Vulpetti et al., "Structural characterization of the GSK-3 $\beta$ active site using selective and non-selective ATP-mimetic inhibitors," Journal of Molecular Biology, vol. 333, no. 2, pp. 393-407, 2003.

[33] F. F. Wagner, J. A. Bishop, J. P. Gale et al., "Inhibitors of glycogen synthase kinase 3 with exquisite kinome-wide selectivity and their functional effects," ACS Chemical Biology, vol. 11, no. 7, pp. 1952-1963, 2016.

[34] F. Di Lisa and P. Bernardi, "Mitochondria and ischemiareperfusion injury of the heart: fixing a hole," Cardiovascular Research, vol. 70, no. 2, pp. 191-199, 2006.

[35] S. Sanada, I. Komuro, and M. Kitakaze, "Pathophysiology of myocardial reperfusion injury: preconditioning, postconditioning, and translational aspects of protective measures," 
American Journal of Physiology Heart and Circulatory Physiology, vol. 301, no. 5, pp. H1723-H1741, 2011.

[36] K. Raedschelders, D. M. Ansley, and D. D. Chen, “The cellular and molecular origin of reactive oxygen species generation during myocardial ischemia and reperfusion," Pharmacology \& Therapeutics, vol. 133, no. 2, pp. 230-255, 2012.

[37] E. J. Lesnefsky, Q. Chen, B. Tandler, and C. L. Hoppel, "Mitochondrial dysfunction and myocardial ischemia-reperfusion: implications for novel therapies," Annual Review of Pharmacology and Toxicology, vol. 57, no. 1, pp. 535-565, 2017.

[38] F. Y. Goh, N. Upton, S. Guan et al., "Fisetin, a bioactive flavonol, attenuates allergic airway inflammation through negative regulation of NF- $\kappa \mathrm{B}$," European Journal of Pharmacology, vol. 679, no. 1-3, pp. 109-116, 2012.

[39] K. Ishige, D. Schubert, and Y. Sagara, "Flavonoids protect neuronal cells from oxidative stress by three distinct mechanisms," Free Radical Biology \& Medicine, vol. 30, no. 4, pp. 433-446, 2001.

[40] G. S. Prasath and S. P. Subramanian, "Modulatory effects of fisetin, a bioflavonoid, on hyperglycemia by attenuating the key enzymes of carbohydrate metabolism in hepatic and renal tissues in streptozotocin-induced diabetic rats," European Journal of Pharmacology, vol. 668, no. 3, pp. 492496, 2011.

[41] B. Kadenbach, R. Ramzan, R. Moosdorf, and S. Vogt, "The role of mitochondrial membrane potential in ischemic heart failure," Mitochondrion, vol. 11, no. 5, pp. 700-706, 2011.

[42] L. Gomez, M. Paillard, H. Thibault, G. Derumeaux, and M. Ovize, "Inhibition of GSK3 $\beta$ by postconditioning is required to prevent opening of the mitochondrial permeability transition pore during reperfusion," Circulation, vol. 117, no. 21, pp. 2761-2768, 2008.

[43] B. D. Sahu, A. K. Kalvala, M. Koneru et al., "Ameliorative effect of fisetin on cisplatin-induced nephrotoxicity in rats via modulation of NF- $\kappa$ B activation and antioxidant defence," PLoS One, vol. 9, no. 9, article e105070, 2014.

[44] T. Eschenhagen, R. Bolli, T. Braun et al., "Cardiomyocyte regeneration: a consensus statement," Circulation, vol. 136, no. 7, pp. 680-686, 2017.

[45] R. A. Kloner, D. A. Brown, M. Csete et al., "New and revisited approaches to preserving the reperfused myocardium," Nature reviews Cardiology, vol. 14, no. 11, pp. 679-693, 2017.

[46] J. Thompson, Y. Hu, E. J. Lesnefsky, and Q. Chen, “Activation of mitochondrial calpain and increased cardiac injury: beyond AIF release," American Journal of Physiology Heart and Circulatory Physiology, vol. 310, no. 3, pp. H376-H384, 2016.

[47] L. Maximilian Buja, "Mitochondria in ischemic heart disease," Advances in Experimental Medicine and Biology, vol. 982, pp. 127-140, 2017.

[48] U. T. Brunk, J. Neuzil, and J. W. Eaton, "Lysosomal involvement in apoptosis," Redox Report, vol. 6, no. 2, pp. 91-97, 2001.

[49] T. Kurz, J. W. Eaton, and U. T. Brunk, "Redox activity within the lysosomal compartment: implications for aging and apoptosis," Antioxidants \& Redox Signaling, vol. 13, no. 4, pp. 511-523, 2010.

[50] S. E. Lee, S. I. Jeong, H. Yang, C. S. Park, Y. H. Jin, and Y. S. Park, "Fisetin induces Nrf2-mediated HO-1 expression through PKC- $\delta$ and p38 in human umbilical vein endothelial cells," Journal of Cellular Biochemistry, vol. 112, no. 9, pp. 2352-2360, 2011.
[51] N. Cho, K. Y. Lee, J. Huh et al., "Cognitive-enhancing effects of Rhus verniciflua bark extract and its active flavonoids with neuroprotective and anti-inflammatory activities," Food and Chemical Toxicology, vol. 58, pp. 355-361, 2013.

[52] R. A. Gottlieb and A. Thomas, "Mitophagy and mitochondrial quality control mechanisms in the heart," Current Pathobiology Reports, vol. 5, no. 2, pp. 161-169, 2017.

[53] S. Takada, Y. Masaki, S. Kinugawa et al., "Dipeptidyl peptidase-4 inhibitor improved exercise capacity and mitochondrial biogenesis in mice with heart failure via activation of glucagon-like peptide-1 receptor signalling," Cardiovascular Research, vol. 111, no. 4, pp. 338-347, 2016.

[54] T. Jin, O. Y. Kim, M. J. Shin et al., "Fisetin up-regulates the expression of adiponectin in 3T3-L1 adipocytes via the activation of silent mating type information regulation 2 homologue 1 (SIRT1)-deacetylase and peroxisome proliferator-activated receptors (PPARs)," Journal of Agricultural and Food Chemistry, vol. 62, no. 43, pp. 10468-10474, 2014.

[55] G. V. Rayasam, V. K. Tulasi, R. Sodhi, J. A. Davis, and A. Ray, "Glycogen synthase kinase 3: more than a namesake," British Journal of Pharmacology, vol. 156, no. 6, pp. 885-898, 2009.

[56] R. Xu, Q. Hu, Q. Ma, C. Liu, and G. Wang, "The protease Omi regulates mitochondrial biogenesis through the GSK3 $\beta /$ PGC$1 \alpha$ pathway," Cell Death \& Disease, vol. 5, no. 8, article e1373, 2014.

[57] A. Valerio, P. Bertolotti, A. Delbarba et al., "Glycogen synthase kinase- 3 inhibition reduces ischemic cerebral damage, restores impaired mitochondrial biogenesis and prevents ROS production," Journal of Neurochemistry, vol. 116, no. 6, pp. 1148-1159, 2011.

[58] A. Ahmad, T. Ali, H. Y. Park, H. Badshah, S. U. Rehman, and M. O. Kim, "Neuroprotective effect of Fisetin against amyloid-beta-induced cognitive/synaptic dysfunction, neuroinflammation, and neurodegeneration in adult mice," Molecular Neurobiology, vol. 54, no. 3, pp. 2269-2285, 2017. 


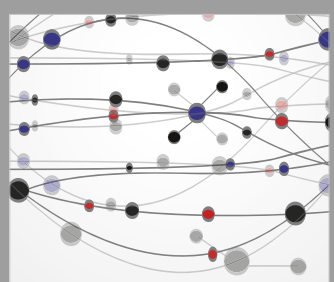

The Scientific World Journal
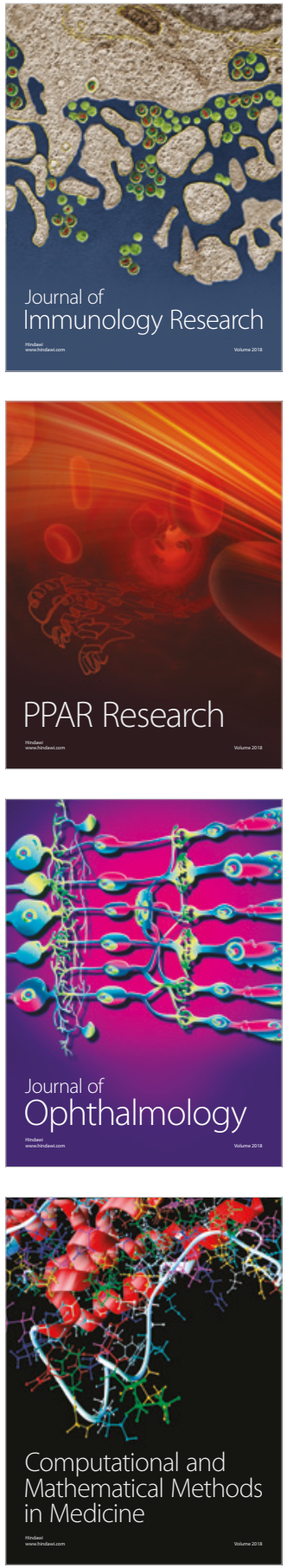

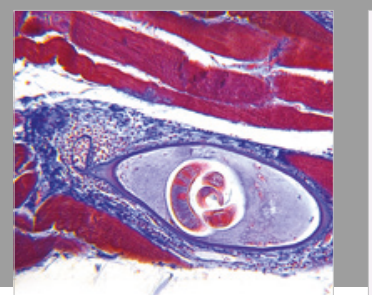

Gastroenterology Research and Practice

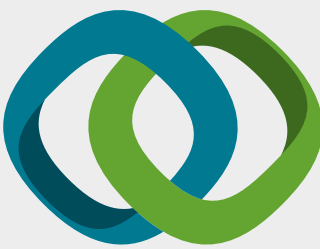

\section{Hindawi}

Submit your manuscripts at

www.hindawi.com
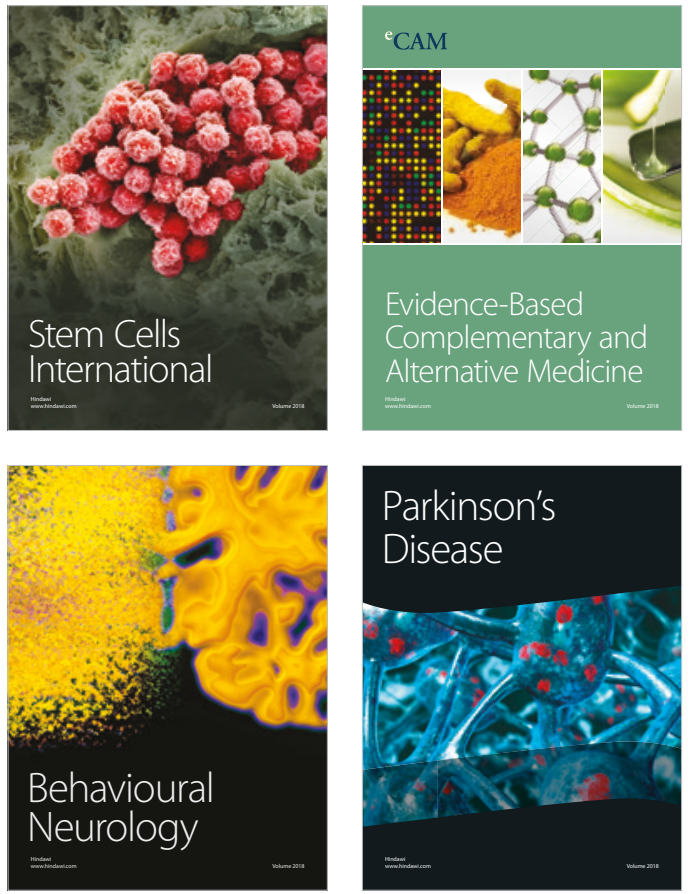

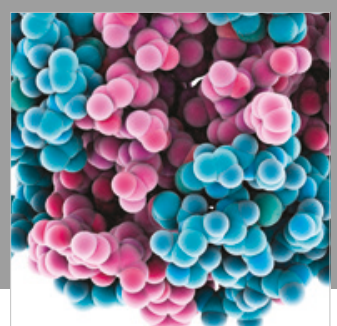

ournal of

Diabetes Research

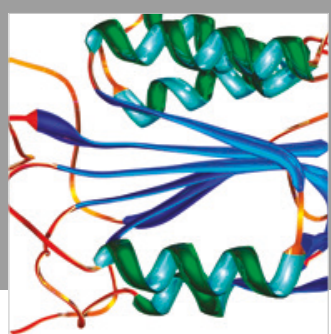

Disease Markers
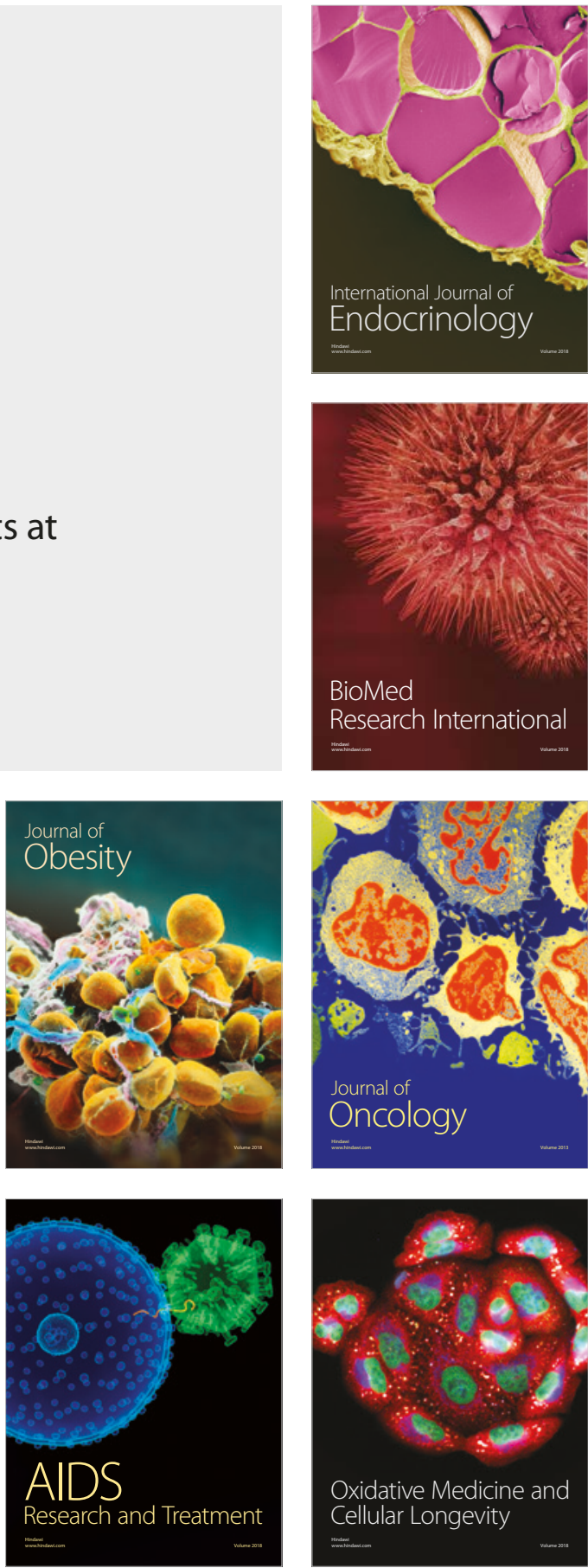